\title{
Changing Rainfall Patterns in an Era of Climate Change: A Multiparameter Spatiotemporal Analysis of Trends \& Impacts for India
}

Praharsh Patel ( $\nabla$ praharshmpatel@gmail.com )

IWMI-Tata Water Policy Program https://orcid.org/0000-0001-6806-317X

Adeel Khan

The Energy Research Institute: School of Advanced Studies

\section{Article}

Keywords: Hydrological Cycle, Spatial Variation in Rainfall, Changing Climatic Patterns

Posted Date: December 2nd, 2020

DOI: https://doi.org/10.21203/rs.3.rs-95659/v2

License: (c) (i) This work is licensed under a Creative Commons Attribution 4.0 International License.

Read Full License 


\section{$\underline{\text { Abstract }}$}

The hydrological cycle that starts with rainfall has been under major threat from the global temperature rise and climatic changes. In India, rainfall changes not only jeopardize water security but also have a major set-back for socioeconomic stability. There have been attempts to decode the changing rainfall patterns in India but most of them conducted at wider spatial resolution (such as national, state, or sub-divisional level) fail to capture the essence of spatial variation in rainfall characteristics. To get a clearer understanding of change in key rainfall parameters, this paper analyses more than 197 million $0.25^{\circ} \times 0.25^{\circ}$ gridded rainfall data points. The fine resolution 117 years (19012017) of daily rainfall data is utilized to test significant spatiotemporal trends in the quantum of rainfall and other key rainfall parameters such as rainy days, monsoon onset and withdrawal dates, occurrences of extreme rainfall events, and frequency of drought and high rainfall years. With an emphasis on changing climatic patterns since perceived climate change onset in the 1970s, the study identifies the regions with significant changes in rainfall patterns by comparing key parameters pre- \& post-1970s. The paper also highlights the major repercussions and challenges for the identified regions with significant changing rainfall patterns.

\section{Introduction:}

Rainfall is the most important event in the hydrological cycle that plays an essential role in providing the fundamental needs of water. Rainfall can be visualized as a gigantic natural machine that filters and provides freshwater from evaporating seawater and other large surface water storage. Rainfall is generally termed as "precipitation" based on the physical form of the downpour has different types of regimes across the globe. In some places such as cold polar

\footnotetext{
${ }^{1}$ Patel, P. M.; IWMI-Tata Water Policy Program, Anand, Gujarat, India. p.patel@cgiar.org/praharshmpatel@gmail.com (Corresponding Author)
}

${ }^{2}$ Khan, A.; The Energy Research Institute - School of Advanced Studies (TERI-SAS) 
India. The diverse rainfall patterns across the globe have a deep influence on the terrain, geology, soil, and many

natural factors, as well as anthropogenic influences characterized by the normal rainfall conditions. The heavy rainfall regions have been inbred with a wealth of rainforests (eg. Amazon and southeast Asian Rainforests) whereas the regions such as Middle-East and North Africa that inherited relatively dry rainfall regime are having a different world altogether. The rainfall is an important climate factor like the temperature in characterizing the regional climate. Climate classification systems such as the widely referred Köppen's classification system use normal (long-term average) annual rainfall for differentiating amongst the climate regimes. (Köppen, 1918) The changing climate due to the influence of Green House Gases (GHGs) is affecting this normality of the rainfall systems across the globe which in turn affects normal lives. (The World Bank, 2012; T H, BM, and M., 2016)

India witnesses a unique seasonal system with three distinct seasons, Winter (October-February), Summer (MarchMay/June), Monsoon (June-September/October). Although the climatic conditions within India vary to a great extent, the majority part of the country receives substantial rainfall during the Indian Summer Monsoon Season (ISMS) between the months of June and September. Except for high-altitude regions of northern and north-eastern parts, the precipitation is normally in the form of rainfall (liquid-state precipitation) in India. (Thus, the words precipitation and rainfall are used interchangeably in this paper). Spatially, India has a great diversity in rainfall conditions, with a few pockets in northeastern hills getting $10,000 \mathrm{~mm}$ of annual precipitation on one extreme whereas the western desert region receives less than $500 \mathrm{~mm}$ of rainfall annually. Besides quantum of rainfall, the onset of monsoon, number of rainy days, and variation in year-on-year rainfall are key variables of rainfall diversity in India.

The substance of good rainfall for the socio-economic stability of India can be gauged from the fact that almost half of the Indian population earns bread directly or indirectly from agriculture and natural resources-based occupations. (Economic Survey, 2019-2020) The World Bank and the FAO estimate that 36.8 percent of the farmland was irrigated in 2013. (FAO, 2016) This leaves almost $2 / 3^{\text {rd }}$ of the agriculture produces dependent heavily on the monsoonal rainfall for water availability for agriculture production to address hunger as well as an associated livelihood for marginalized communities. To put the gravity of the situation raised due to climatic changes in financial terms, the UN Office on Disaster Risk Reduction has estimated that India has direct losses due to climate change are USD 79.5 Billion between 1998 and 2017, and the majority of the losses were due to rainfall related events such as floods and droughts. (Wallemacq, UNISDR, and CRED, 2018) As per the Intergovernmental Panel on Climate Change (IPCC) report ( Solomon, Susan and Manning, Martin and Marquis, Melinda and Qin, 2007), future climate change is likely to affect agriculture, 
increase the risk of hunger, water scarcity, and lead to more rapid melting of glaciers. Changes in rainfall in India due

to global warming will influence the hydrological cycle and the pattern of stream flows (Kumar, Jain and Singh, 2010).

This will inadvertently affect freshwater availability for consumption in many river basins in India (Gosain, Rao and Basuray, 2006).

Apart from affecting the volume of water availability, changing rainfall patterns may distort rainfall distributions across spatial rainfall regimes. The initial evidence for the same comes from the daily rainfall data of central India analyzed by (Goswami et al., 2006). It shows a significantly increasing trend in the frequency and magnitude of the extreme rain events as well as a significantly decreasing trend for the normal rainfall events during $1951-2000$. Recent studies show that, in general, the frequency of more intense rainfall events in many parts of Asia has increased, while the number of rainy days and the total annual amount of precipitation has decreased. (Khan, Singh and Rahman, 2000), (Shrestha et al., 2000),(Monirul Qader Mirza, 2002)(Lal New Delhi (India)], 2003), (Dash et al., 2007)

Rainfall is discontinuous and highly localized event that varies vastly over space and time; thus, a holistic understanding of rainfall trends spatially and temporally is essential for effective water management, especially in the context of growing climate and rainfall variability owing to climate change. To check rainfall trends in India, attempts have been made at national and regional scales. A Sub-division (India has been divided into 36 sub-division zones based on meteorological conditions) level analysis of the month-wise quantum of rainfall data by Mondal et al (2014) reported that many parts of Western India and Central India received a very high negative change rate for monsoon rainfall, while Central and North-eastern parts of India observed a highly decreasing change rate. One down-side, these composite trends either studied through the weighted averages at the national or sub-divisional level seldom convey the intricate and diverse patterns observed at the granular level. To catch the essence of the variety of Indian geography, this study takes a much more comprehensive view by looking at the temporal and spatial rainfall trends all across mainland India. Granular scale rainfall studies are confined to the analysis of annual and seasonal series for individual or groups of stations confined in some disjoint geographical clusters. (Taxak, Murumkar and Arya, 2014; John, 2018; Nandargi and Gupta, 2018; Panda and Sahu, 2019; Anand and Karunanidhi, 2020; Patakamuri, Muthiah and Sridhar, 2020) These studies are not compiled for national scales; thus, they fail to show repercussions of rainfall trends and anomalies at a larger scale. Furthermore, rainfall is a discrete event. Thus, it is equally essential to understand how well rainfall is spatially distributed on rainy days and the total quantum of rainfall. 
To create a much clearer understanding of the rainfall quantum, rainy days and other relevant quantities; an analysis of finer-scale daily rainfall data across India is an important step towards fetching information for policy preparedness for underlying risks. To address this need, the current analysis focuses to gauge rainfall characteristics and trends for the entire geography of India at a much finer scale (i.e. $0.25^{\circ} \times 0.25^{\circ}$ scale gridded data) and time-period spanning 117 years (1901-2017). This paper analyses temporal and spatial rainfall trends and variation in the key rainfall parameters with interest to decipher significant trends since major climatic changes are believed to be initiated. The finer scale analysis (more localized) will enable identification of spatiotemporal trends that get divulged while compiling and analyzing data at coarser scales such as district, state, or national level. Many water and agriculture-related understanding such as crop suitability, crop failure, crop water requirements and irrigation availability, etc. require localized information. Policymakers, as well as grassroot workers, need fair clarity on the meteorological changes in their area as granular as possible so that adequate preparedness for mitigation and adaptive measures can be planned.

\section{Data in Discussion \& Analysis Methods:}

\section{$2.1 \quad$ Data}

Out of various spatial and temporal data series available for India rainfall. The most cited and preferred data is curated by the Indian Meteorological Department (IMD) that has compiled daily rainfall precipitation data from 1901 to 2017 at a finer scale of $0.25^{\circ} \times 0.25^{\circ}$ pixels. (Pai et al., 2014) For our analysis, we have used this data available for 117 years for $365 / 366$ days of a year from 1901 to 2017 . Data is arranged in $135 \times 129$ grid points. The first data in the record have latitude and longitude: $6.5 \mathrm{~N} \& 66.5 \mathrm{E}$, the second is at $6.5 \mathrm{~N} \& 66.75 \mathrm{E}$, and so on. The last data record corresponds to $38.5 \mathrm{~N} \& 100.0 \mathrm{E}$. The yearly data file consists of $365 / 366$ records corresponding to non-leap/ leap years. The unit of rainfall is in millimeter $(\mathrm{mm})$ with an observation accuracy of $1 \mathrm{~mm}$. In total, there are 42,734 days of data, with each day having 4621 pixels for each day. This sums up as 197,473,814 pixels analyzed for analyzing each rainfall parameter of interest.

Annual Rainfall data is prepared by adding monthly (January - December) rainfall for each pixel. Similarly, the same data set is compiled to get Monthly and Monsoonal (June-July-August-September) rainfall figures. The data curation, preparation, and analysis are entirely done using open-source statistical analysis software R. (Appendix 2)

\subsection{Methods}


The objective was to examine significant annual rainfall precipitation trends at the micro-level over the past 117 years.

The first step towards understanding the normal situation, the average of rainfall and rainy days over 117 years long time series data are calculated. The total cumulative volume of rainfall each year across all the observational pixels. This is calculated by taking the cumulative sum of the product of quantum of rainfall (in $\mathrm{mm}$ ) multiplied by the area of the pixel $\left(\mathrm{km}^{2}\right)$. (Eqn 1)

$$
V_{y}=\sum_{\forall p}\left(r_{p} X A_{p}\right) / 10^{6}
$$

$$
\begin{array}{r}
p=\text { Data pixel } \\
V_{y}=\text { Volume of Rainfall }(B C M) \\
r_{p}=\text { Quantum of Rainfall in a pixel } p(\mathrm{~mm}) \\
A_{p}=\text { Average Area represented by a pixel } p\left(\mathrm{~km}^{2}\right)
\end{array}
$$

Change-point analysis, As the analysis warrants for the understanding of the noteworthy changes in rainfall patterns over the 117 years, the Pettitt test (Pettitt, 1979) (Appendix 1) is used to get a sense of the change in the rainfall extreme events that are one of the major showpieces of the climatic changes. The test is a distribution-free rank-based test, used to discover noteworthy changes in the mean of the time series. (Jaiswal, Lohani and Tiwari, 2015; Javari, 2016; Praveen et al., 2020)

For trend observation, Mann-Kendall (MK) test (Kendall, 1975) is used. MK test is a non-parametric test to identify significant monotonic trends without having to assume any underlying distribution. It has been widely used (Yu, Zou and Whittemore, 1993; Douglas, Vogel and Kroll, 2000; Yue and Hashino, 2003) to analyze trends in hydrological and climatic variables, such as temperature, precipitation, and streamflow in the context of climate change. One of the major reasons to use non-parametric tests in the present study is that they can be used on independent time series data and are also not sensitive to outliers.

P. K. Sen developed the innovative trend analysis to detect the magnitude of the trend in meteorological, hydrological, and environmental variables (Sen, 1968). Sen's Estimate, coupled with the MK test, is an effective statistical tool for analyzing time-series meteorological data. Unlike the linear ordinary least square method largely used for detecting the trend, Sen's Method ${ }^{1}$ is non-parametric. This method has been frequently applied to estimate the direction (increasing or decreasing) and the magnitude of the hydro-meteorological time series trend, and details are available 
in (Yu, Zou and Whittemore, 1993; Yue and Hashino, 2003; Partal and Kahya, 2006). For better Spatial understanding

123

\begin{tabular}{|llll}
\hline Category no. & Percentile & Corresponding rainfall & Description \\
\hline 1 & $<10$ th & $<5 \mathrm{~mm}$ & Dry \\
\hline 3 & 10 th-60th & $5-20 \mathrm{~mm}$ & Low rainfall \\
4 & 60th-90th & $20-35 \mathrm{~mm}$ & Moderate rainfall \\
5 & 90 th-95th & $35-50 \mathrm{~mm}$ & Heavy rainfall \\
6 & 95 th-99th & $50-65 \mathrm{~mm}$ & Very heavy rainfall \\
7 & $>99$ th & $65-100 \mathrm{~mm}$ & Extremely heavy rainfall \\
\hline
\end{tabular}

of pockets with significant trends (MK Test, $p$-value $<0.05)^{1}$, Maps are produced with Sen's estimate value for pixels observing significant trends. $(p<0.05)$.

Extreme Events Analysis for observing how the composition of extreme rainfall events are changing over the years, a total number of extreme rainfall events ( $>65 \mathrm{~mm}$ in a day) and very extreme rainfall events ( $>100 \mathrm{~mm}$ in a day) are summed for each year across India and plotted with Local Polynomial Regression (LOESS) Regression to understand the trend over the years. Table 1 gives an understanding of the merits of the rainfall event classifications.

Table 1. Different categories of rainfall based on the percentile value and corresponding rainfall amounts. (Varikoden and Revadekar, 2019)

Mathematical Formulation: Petitt's Test, Mann Kendall Test, Sen's Estimator, LOESS Regression: Annexure 1

\subsection{Analysis}

The paper aims to take up spatial and temporal analyses of the rainfall parameter to capture the nuances and peculiarity of the diverse climatic regions of India. The wholistic quintessence understanding of rainfall requires several rainfall parameters that are beyond the scope of this paper. To get an as good understanding as possible, the analysis focuses on a few important rainfall parameters such as Annual Total Quantum of Rainfall \& Total Number of Rainy- 
days. With a special interest in Monsoonal Rainfall characteristics, the Onset (defined as first day of Months JuneSeptember when precipitation is more than $2.5 \mathrm{~mm}$.) and Withdrawal (defined as the last day of Months June - October when precipitation is more than $2.5 \mathrm{~mm}$.) dates of Monsoon are included in the analysis. Other important parameters considered to check the changing composition of normality are the extreme rainfall events and the annual frequency of dry (Total Annual Rainfall $<75 \%$ of Long-term Mean) and wet/above normal rainfall (Total Annual Rainfall $>125 \%$ of Long-term Mean) years in 20-20 years spell.

The crux of this 2-dimensional Spatiotemporal analysis (Dimension 1: Time, Dimension 2: Space) is based on two pillars.

1) Along with the total quantum of rainfall over the years, we have used 5 rainfall parameters for rainfall characterization,
i) Total annual rainfall,
ii) Total number of rainy days,
iii) Onset and withdrawal of rainfall during wet months of monsoon
iv) Extreme rainfall events.
v) Dry and wet year frequency across 20-year time periods

2) Compare the long-term trends of these parameters before the climatic change with the era since the beginning of climatic changes.

To select a breakpoint, the year considered as the point of significant change in the climatic trends, we use literature as well as a change-point analysis of extreme rainfall events results. To capture a single point for change in the rainfall timeline, we need to use a parameter that can better capture the anomalistic behavior in rainfall when aggregated at the national level. The extreme rainfall events are opted for the change point analysis as they better emulate the changing rainfall pattern which might not be easily captured through the aggregation of the total quantum of rainfall or rainy days across data points. For example, a region may have seen a similar amount of rainfall say $500 \mathrm{~mm}$ over the years with an average of 20 rainy days without any significant changes over the years. But there can be a considerable change in extreme events as now the region experiences 5 days with $>65 \mathrm{~mm}$ of rainfall as compared to 1-2 days a few years back. Also, the sum of extreme events is easier to aggregate over the entire geography of India as compared to aggregating rainy days and better parameters to capture anomalies as compared to the quantum of rainfall. 
The change point analysis revealed that extreme rainfall events have a change point around the year 1969 . These results are coherent with important literature results of (Zhou et al., 2009) which indicates the negative heating in the central and eastern tropical Pacific and increased monsoon condensational heating in the equatorial Indian Ocean/Maritime Continent Studies since the late 1970s has been affecting the Indian rainfall characteristics. A detailed analysis of sub-division level monthly rainfall data (Praveen et al., 2020) established that almost all of the sub-divisions in India detected the change in trend and high variability of rainfall after 1970 . This capitulates the basis of this paper considering the pre-1970s and posts 1970s trends of the rainfall parameters. Two separate sub-series (1901-1970) and (1970-2017), both leaving sufficient years of observations (70 years and 48 years resp.), are further analyzed for significant trend detection analysis.

\section{$3 \quad$ Analysis and Inferences:}

\subsection{Preliminary Analysis of Rainfall in India}

\subsubsection{Dimension 1: Temporal Variation of Rainfall Aggregated at National Scale}

quantum of rainfall aggregated at a national scale (Fig 1 (a)) and ii) plotting monsoonal as well as the annual quantum of rainfall (Fig 1 (b)). This initial analysis shall help to comprehend normal rainfall conditions in India but an aggregation of data at the national scale shall not reflect any intra-annual observable changes across regions. The annual national rainfall average plotted in Fig 1 (a) shows the total cumulative volume of the water precipitated each year across all the observational pixels along with the local regression curve (LOESS Regression). The total quantum of rainfall is calculated by taking the cumulative sum of the product of quantum of rainfall (in mm) multiplied by the area of the pixel $\left(\mathrm{km}^{2}\right)$. (Equation (1))

At a national scale, rainfall shows a periodic behaviour with an alternate cycle of higher and lower than normal rainfall. These alternate decadal patterns are suggestive of the absence of significant monotonic trends at the macro scale. The MK-Test for the annual rainfall data series does not show a significant increasing trend $(p>0.05)$, but a LOESS Regression trendline (red line in Fig $1(A)$ ) suggests the total quantum of rainfall is on an average 200 BCM less rainfall than its peak in the 1940s. Although the observation cannot be classified as a trend, the plot certainly indicates there have been more frequent drier years in the recent decade as compared to a few decades ago. Fig. 1(B) shows how the 


\section{(A): Annual Total Quantum of Rainfall}

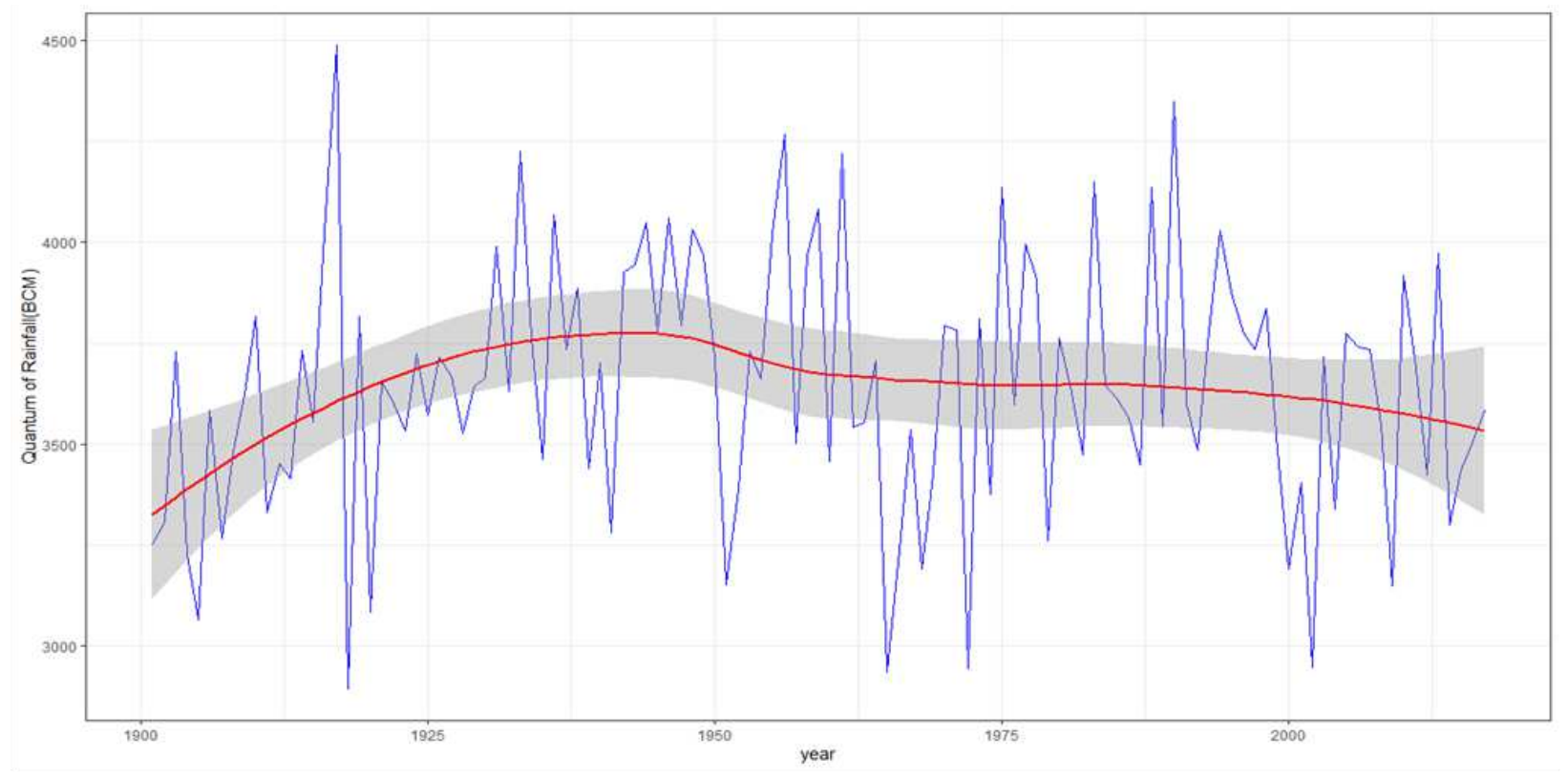

(B): Aggregated Annual and Monsoon Rainfall in India

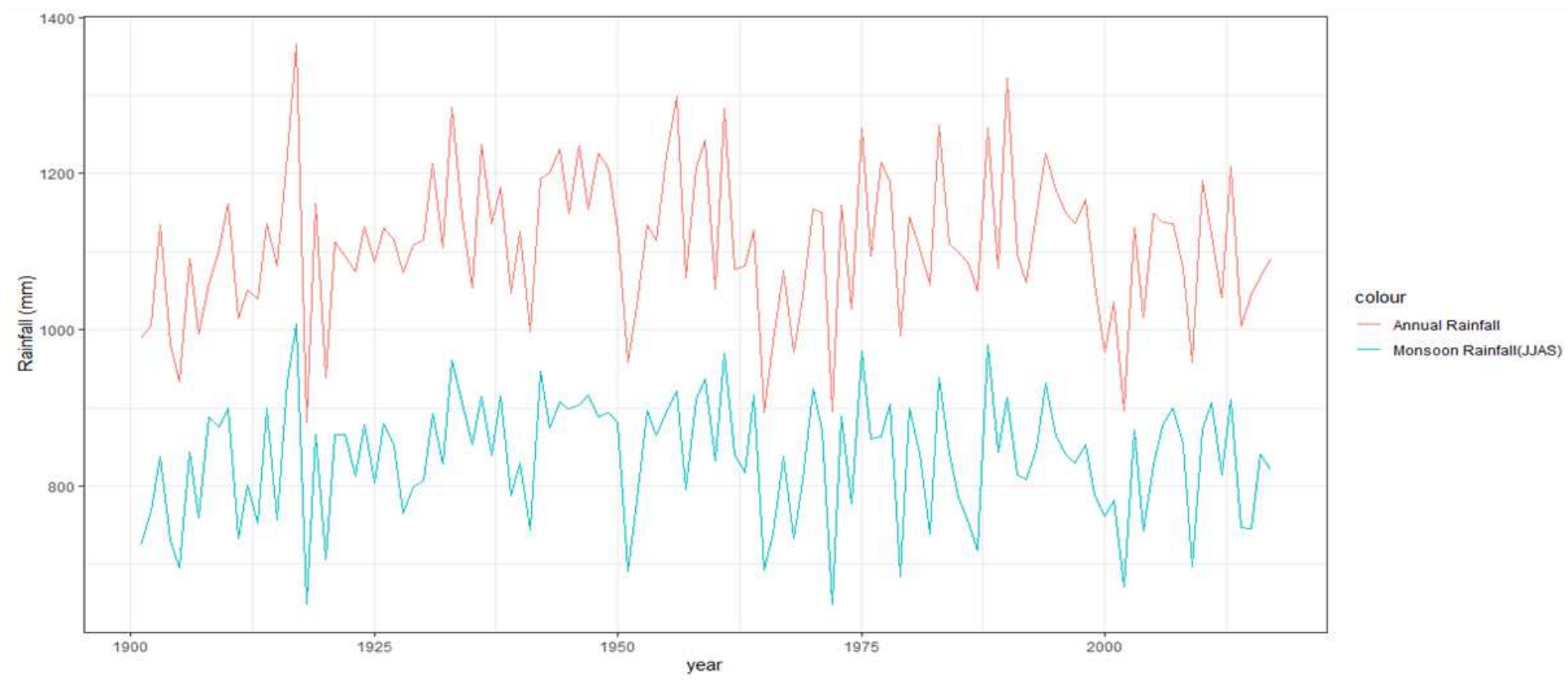

Fig 1: Observed Annual Rainfall (A) Total Estimated Volume of Rainfall (BCM) (B)Aggregated Annual Rainfall (mm).

\subsubsection{Dimension 2: Spatial Variation of Rainfall Cumulated Over the Years.}

Just the total quantum of rainfall aggregated at the national level doesn't help with comprehending normal rainfall conditions across the large and diverse landmass of India. The essence of the finer resolution data used in the paper relies on meticulous spatial analysis. To understand spatial rainfall variation, we have visualized normal (An annual 
average of the parameters from 1901-2017) annual total Rainfall, Number of Rainy-days (days when the region receives more than $2.5 \mathrm{~mm}$ of precipitation.), Onset Date of Monsoon, and Withdrawal date of Monsoon. (Fig 2 \& 3)

201 The pixelate data visualized in Fig 2 shows that the spatial distribution of precipitation in India and unveils the high spatial rainfall variability observed across India. The quantum of rainfall as well as rainy days both vary to a great extent within India. Also, Fig 2 (D) clearly shows the majority of India receives most of the precipitation during the Indian Summer Monsoon Season (ISMS); thus, the good rainfall during the monsoon season is an important factor for overall annual water security and stability of agriculture and livelihood. The exceptional regions that do not follow the general trend of monsoon and rainfall distribution are the Southern tip (State of Tamilnadu), Some parts of the Eastern Coast (Rayalseema, Orissa), and the North-Eastern Mountainous Region. These regions also experience retreating monsoon showers after the end of ISMR in most other parts of India. Fig 3. Shows the movement of monsoon across India and the normal time of monsoon onset and withdrawal. The ISMS initiate from the cast of southwestern-western state Kerala and moves towards North-East direction. Within the next 30 days, it covers the entire country leaving the western desert districts last to receive the first shower. The season withdrawal follows a complementary path as the western districts are the first to experience the end of the monsoon season and gradually the monsoon retreats following the path it followed for the onset in a reverse direction. The northernmost region of Leh and Ladakh are the high-altitude cold deserts that are beyond the great Himalayan mountain chain that prohibits easy manoeuvre of moist winds responsible for rainfall. Thus, the region receives scanty and volatile monsoon. (See parameters exhibited in Fig 
A) Annual Average Rainfall (1901-2017)

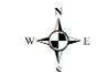

\section{C)} Average Rainfall per Rainy day (1901-2017)
B) Average Rainy days (1901-2017)

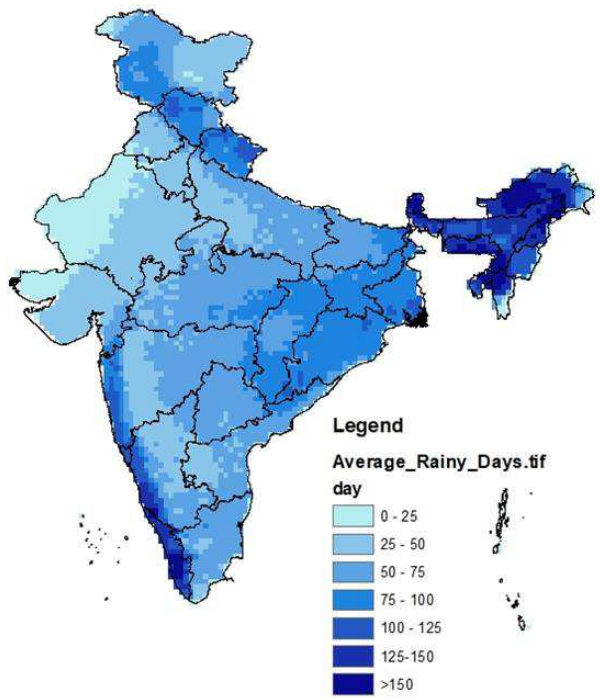

$\begin{array}{llll}0 & 265 & 530 & 1,060 \text { Kilometers }\end{array}$ Coordinate System: GCS WGS 1984 Datum: WGS 1984
Units: Degree

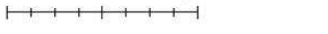

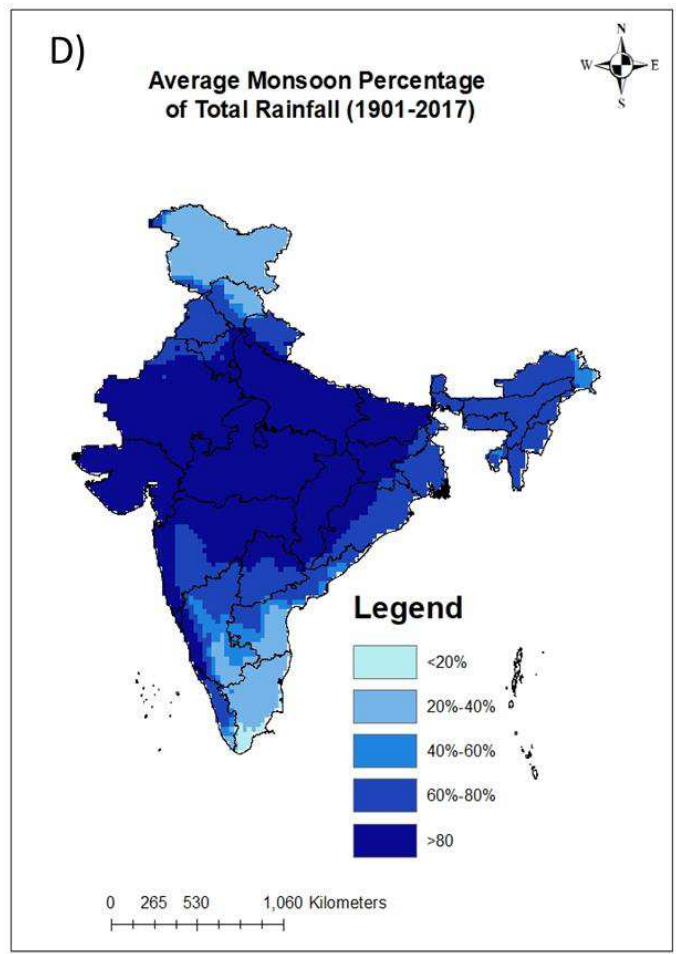



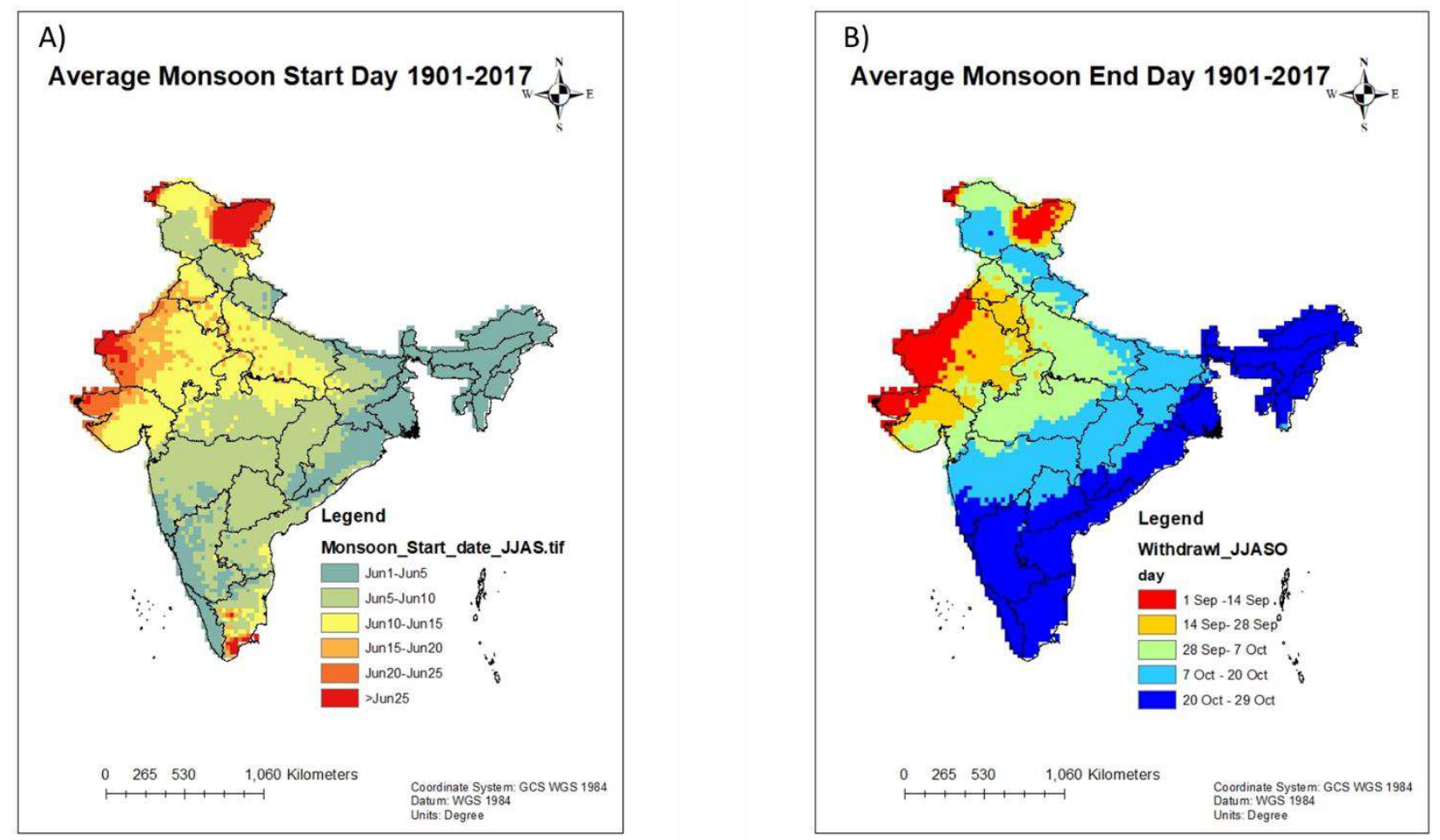

Fig 3: Normal (Average 1901-2017) onset (A) and withdrawal dates (B) in India.

\subsection{Normal Spatiotemporal Variation in Rainfall}

Taking the first step towards combining the two extents of the analysis, space, and time, we need to understand how

the rainfall distribution normally varies over the years as well as space. There is always some year-on-year variability in rainfall within spatial pockets, which is normal in observing any natural phenomenon. Thus, the variation over the years also becomes a key parameter in defining the rainfall characteristics. For instance, the western desert districts of India receive scanty and highly volatile monsoonal rainfall. Every $4^{\text {th }}$ or $5^{\text {th }}$ year is a dry year and on the other side, there is also an equal probability of very high rainfall every $4^{\text {th }}$ or $5^{\text {th }}$ year in these districts. Whereas central and east to central parts of India don't have that high rainfall variability. They normally experience a dry year once in 10 years. We are quantifying this variability across the pre-1970s and post the 1970s for each pixel using a coefficient of variation $[\mathrm{CV}=$ (Standard Deviation)/Mean]. Overall, rainfall aggregated at the national level shows the standard deviation of rainfall as $95.3 \mathrm{~mm}$ against the mean rainfall of $1108.7 \mathrm{~mm}$. (Data in Fig 1) The coefficient of variation for the composite rainfall stands at 8.6 percent. 
The majority of Indian pockets have a CV in the range of 20-40 percent, mostly around 25 percent. (Fig 4) Except a few

western hot dessert and regions and norther cold desert areas of Leh and Ladakh that show very high rainfall variability

that explains their desert characteristics to some extent. The gradient of annual variation in rainfall is decreasing

almost continuously moving eastward. Even a few pockets in the north-eastern regions of India also experience high

rainfall and also high variability too. Variation in rainfall is expected but high variability increases the uncertainty about

the availability of water for the annual cycle of agriculture and other domestic needs. The first evidence for the

changing rainfall patterns can be witnessed from Fig 4 . Fig 4 (c) has much of an area in red as compared to the area in

blue. The north-most region showing reduced variation is the region (State of Jammu and Kashmir) where the average

rainfall has decreased considerably. This indicates the most increased variation in the quantum of rainfall received

be simply attributed to a shorter time-period length.
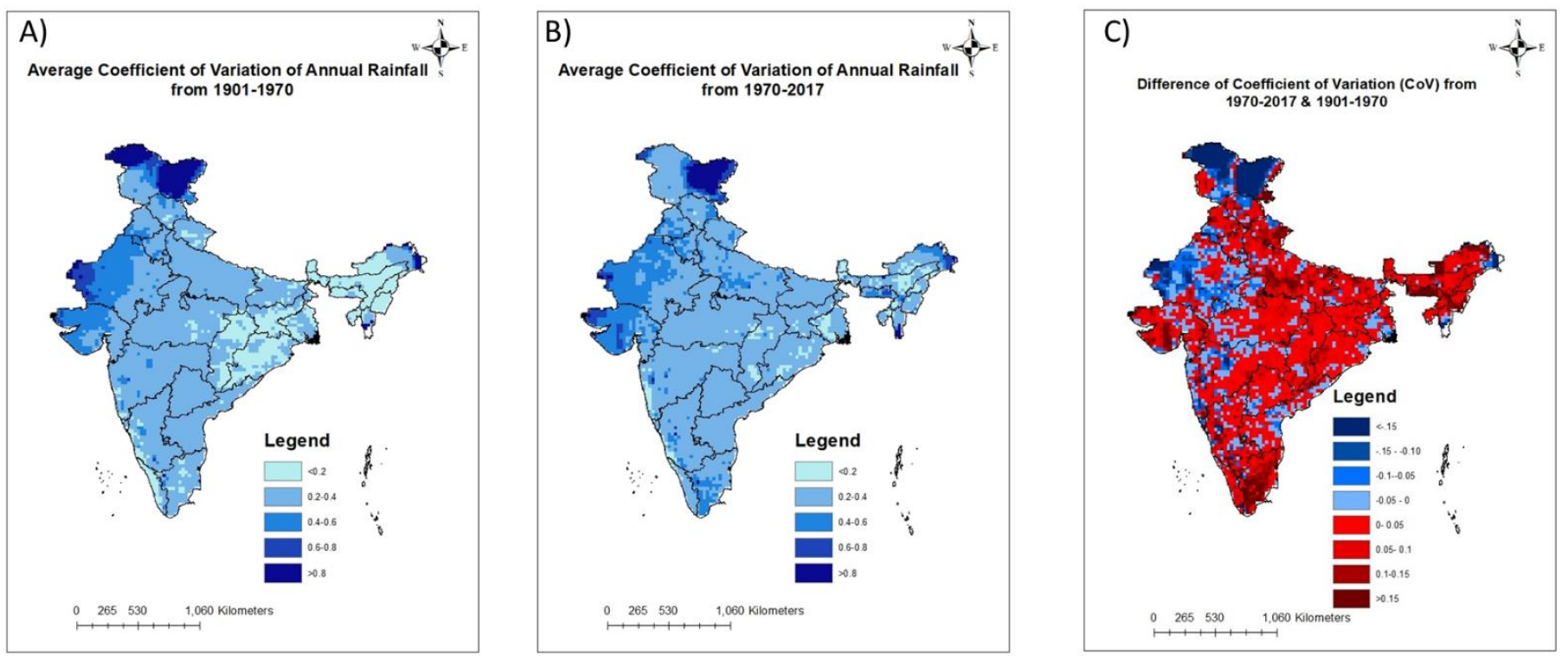

Fig 4: Coefficient of Variation (CV) of the quantum of Rainfall (A) before 1970, (B) after 1970, (c) difference in Coefficient of variation 1970-2017 vs 1901-1970 (Red: Increased variation, Blue: Reduced Variation).

\subsection{Analyzing the Significance of Rainfall Trends:}

Section 3.1 and 3.2 form the basis of normal rainfall conditions in India. This section focuses on identifying the spatial pockets with a significant temporal trend in key rainfall parameters. The trend here is defined as a direction (positive or negative) in which the key rainfall parameters being assessed are changing over the years, and the significance of the trend is statistically derived through Mann-Kendall Test explained earlier. The vital objective behind this set of analyses is to check if there are spatial regions that have exhibited significant change since 1970, the start of an era of 
climatic changes. Apart from showing empirical evidence for the impact of climatic changes through rainfall, this shall also help with understanding the implications of the rainfall changes at a granular scale in India.

\section{3.3.1 Trend in Annual Total Quantum of Rainfall}

The most noticeable and imperative parameter to understand the rainfall trend is the total quantum of rainfall. Figure 5 shows the MK Trend Significant regions highlighted with estimated Sen's Slope. Regions highlighted with red-shade are experiencing a significant (the trend is considered significant if the MK Test for the data series has $p$-value (probability of slope of the trend $=0$ ) $<0.05$. (Appendix 1)) decreasing rainfall trend whereas the regions highlighted with blue-shade have witnessed a significantly increasing trend in the respective periods. Fig 5 infers that some pockets in peninsular India have experienced better rainfall in the post-1970 era. The figure clearly shows a high spatial variation in the rainfall trends within the same state or sub-division and vouches for the importance of granular analysis for rainfall trend analysis. The better granularity of data with 4621 pixels within the image helps in classify and determine intra-regional changes in the rainfall quantum and pattern which wouldn't have been possible with aggregated data at coarser-scale and. Here we can quote an example of Jammu \& Kashmir State, the northern-most state. The state encompasses pockets with significant increase as well as decrease quantum of rainfall trend but when the data aggregated at the state-level the mean values will obliviate these trends. Thus, the earlier study by Mondal et al. (2015) at the sub-division level fails to identify the trend.

Fig 5 shows the western desert regions of Kutch and North Gujarat and Rajasthan has a slightly better quantum of rainfall. The important information is revealed from the north Indian Planes or the region known as Ganga-Yamuna Flood Planes (GYFP) stretching in the States of Uttar-Pradesh, Bihar, and West Bengal. GYFP has seen a sharp decreasing trend for the annual quantum of rainfall post-1970. The figures illustrate that a few pockets down south do have an increasing trend but mostly it is not statistically significant $(p>0.05)$. Both these points combined support the climate change hypothesis which proposed the increasing mean temperature shall adversely affect the rainfall in the North Indian Planes and the Peninsular part of India may get sparsely better rainfall characteristics. (The World Bank, 2012; Reyer et al., 2017). 

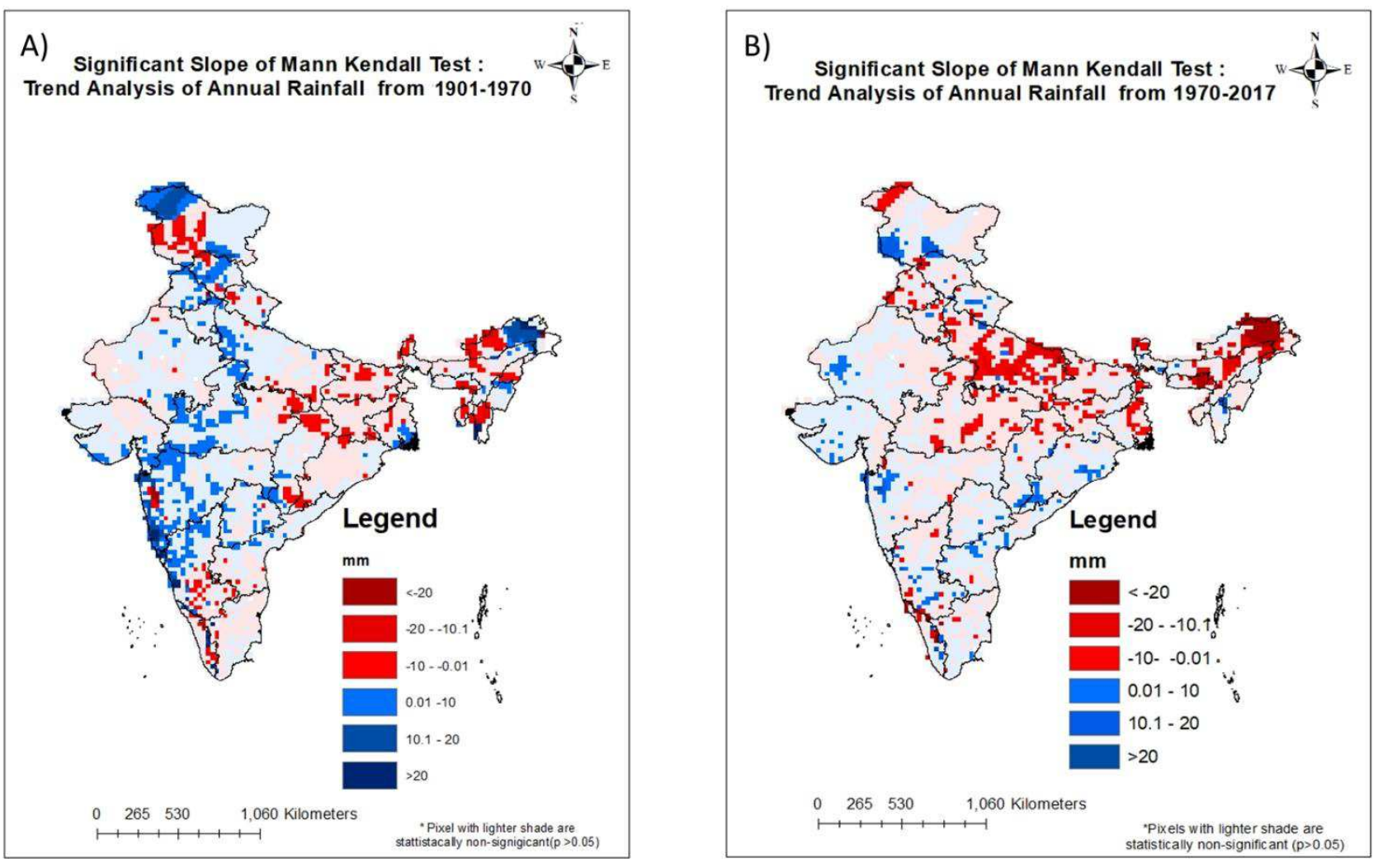

Fig 5: Quantum of Rainfall significant trend and Sen's Slope Estimates. A) 1901-1970 \& B)1970-2017

\subsubsection{Trend in Number of Rainy days}

It is possible the region has experienced the same number of rainfall but the rainfall is more squeezed in terms of rainy days. As stated earlier, rainy days may help in identifying deviation from normal rainfall. The MK Tests for the annual total number of rainy-days show that most North and Eastern India has experienced a significant declining trend of the total number of rainy-days post-1970 which is inconsistent with the pre-1970 period. (Fig 6) Comparison of Fig 5 \& 6 shows that even a few regions (in states like Madhya Pradesh, Orissa, Jharkhand, Bihar, and West Bengal) haven't witnessed a significant decreasing trend for a total quantum of rainfall have experienced a decreasing trend for the number of rainy days. This advocate shrunk rainfall spells within rainfall season and supports arguments put-forward around increasing the extreme events (high rainfall in a shorter time) in India that are further discussed in section 3.4. (Dube and Rao, 2005; Goswami et al., 2006; The World Bank, 2012; Praveen et al., 2020)

Due to the reduced number of rainy days, the regions may experience frequent agriculture droughts even if they are not facing the hydrological or meteorological drought. The shorter wet spell followed by a longer dry spell leads to crop failure even during the meteorologically good rainfall year. Shorter rainfall spell shall also lead to less natural percolation of the rainwater and higher surface run-off that may over flood the dam capacities but does not recharge 


\subsubsection{Trend in Monsoon Onset \& Withdrawal}

A few of the most important rainfall parameters for agriculture activities are the onset and withdrawal dates for the monsoon. Many agrarian decisions such as cropping patterns, use of irrigation, demand for seeds, and fertilizers heavily depend on the onset of monsoon. The anomalistic onset of the monsoon dates can jeopardize agrarian planning for states, markets, and farmers. This can even sink the cost of a decision taken based on the normal rainfall onset time such as the purchase of seeds of the crops to sow. As stated earlier, India's monsoon starts from the southwestern coast of Kerala in the first week of June and spreads across India in the next 30-40 days, and covers major parts of India. (Fig 3)

The worrying trend revealed in Figure 7 (B) shows that the trend has been anomalous in a different part of India. Although the onset of monsoon in the Kerala coast has not seen any deviation, the eastern regions are receiving early monsoon onset (red pixels), whereas the western part is experiencing a late arrival trend (blue pixels). The comparison of Fig 7 (A) and (B) suggests early onset in peninsular India and delayed onset in the north and central India are predominantly experienced post-1970s. Unlike rainy days, onset dates do not show a widespread changing trend across India.
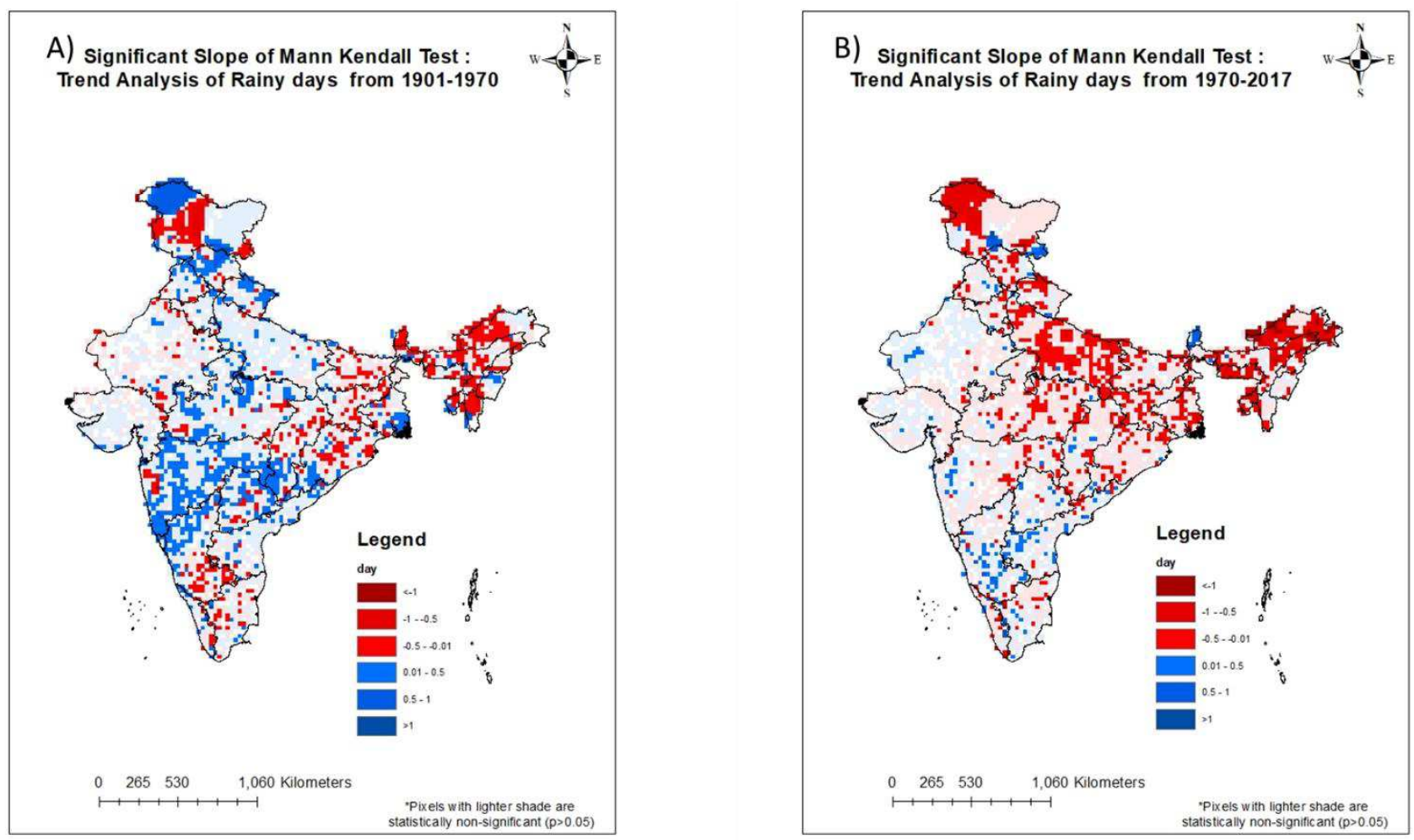
A)

Significant Slope of Mann Kendall Test : Trend Analysis of Monsoon Start Date (JJAS) from 19701-1970

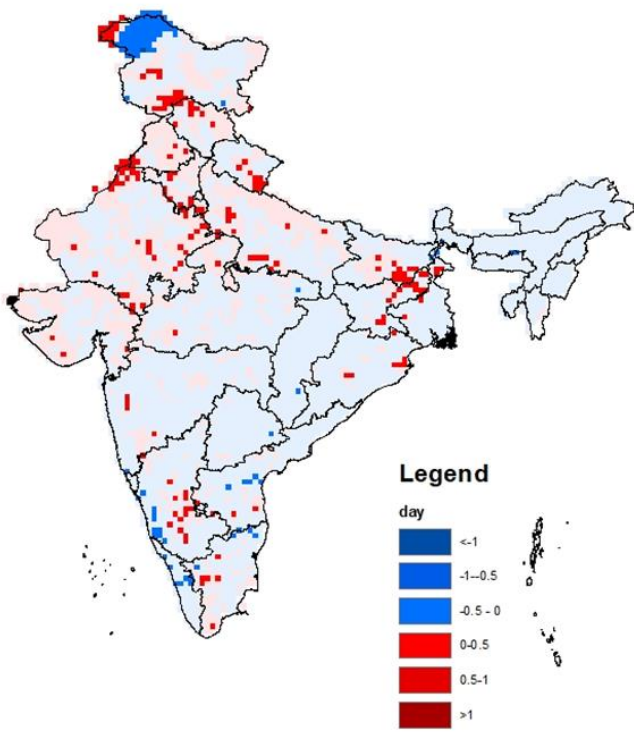
shrinking monsoon season altogether in India.

\section{B)}

Significant Slope of Mann Kendall Test :

Trend Analysis of Monsoon Start Date (JJAS) from 1970-2017

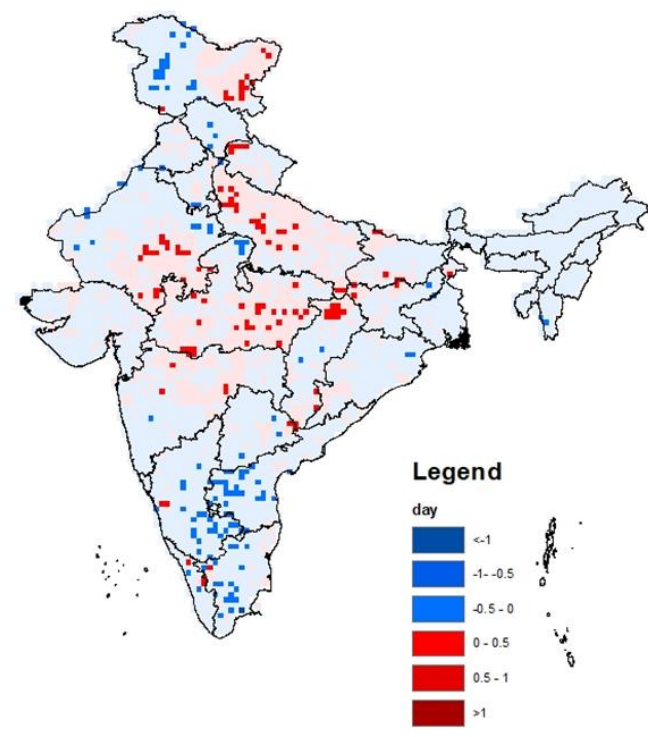

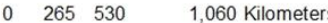

Pixels with lighter shade are statistically non-signific ant $(p>0,05)$

Fig 7: Onset of Monsoon significant trend and Sen's Slope Estimates. A) 1901-1970 \& B)1970--2017

As the onset dates are important for agrarian decisions, the withdrawal of rainfall is important to observe for the agriculture output. Very early withdrawal can deprive the crop of the crucial water needs before harvest that can impact the yield to a great extent whereas the delayed showers can be detrimental for harvest-ready crop-fields and spoil the production in the Indian agrarian sector that faces scarcity of storage infrastructure. The end date for the monsoon rainfall map is predominantly shaded-red (early withdrawal) but the trend is statistically inconclusive ( $p>0.05$ ) post-1970s except for a few pockets. (Fig 8) Although there are significant changes in the onset of monsoon dates, the withdrawal dates do not show any significant change over the years. This supports the phenomenon of 

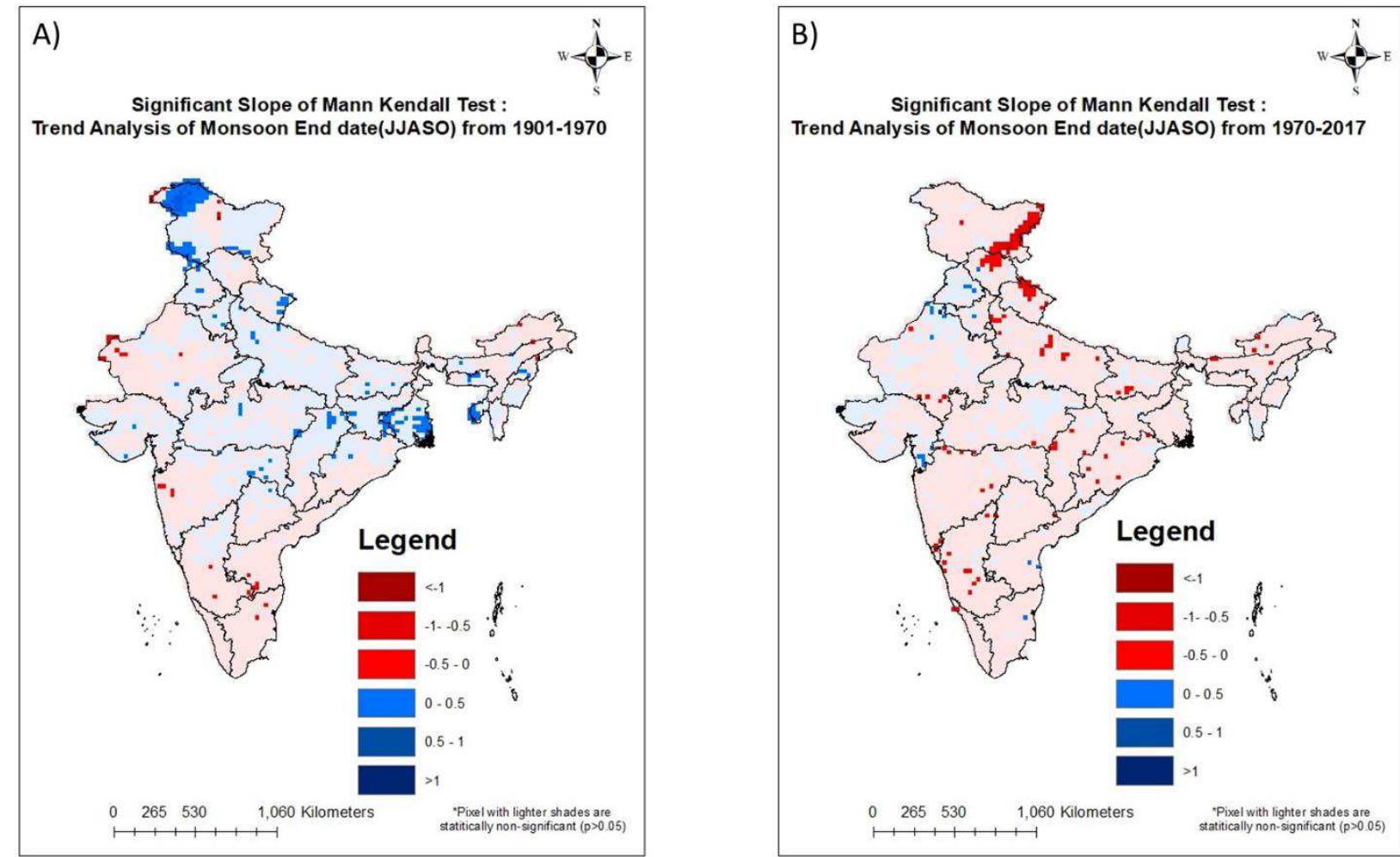

Fig 8: Withdrawal of Monsoon significant trend and Sen's Slope Estimates. A) 1901-1970 \& B)1971-2017

\subsection{Trends in Extreme Events}

This set of rainfall parameters cannot follow the pattern used for analyses in section 3.3 due to the peculiarity of occurrence of high rainfall events are not continuous and the dry or wet years are identified based on the cumulative annual rainfall and they are mostly understood based on the frequency of their occurrences.

\subsubsection{Dry and Wet year Frequency}

The annual rainfall is discretely having different patterns each year, and there are certainly some years having distinctly higher than normal or much lower than the normal rainfall. Classifying the years in which the area has received a 25 percent deviation from the normal rainfall as dry (less than normal) or wet (more than normal) years, a definition adopted by NRAA (2020), we have compared the vicennial changes in the frequency of these years are plotted in Fig 9.

It is evident from Fig 9 (A) that many parts of India are experiencing an increased frequency of dry years recently especially after the 1980s. This is also reflected in the darker shade of Northern India that has shown a decreasing rainfall trend as discussed earlier. The observation for the wet years shows that some parts of western parts have seen a rise in wet years in the 2001-2017 time period. These are mostly the dry regions but northern and eastern India has 


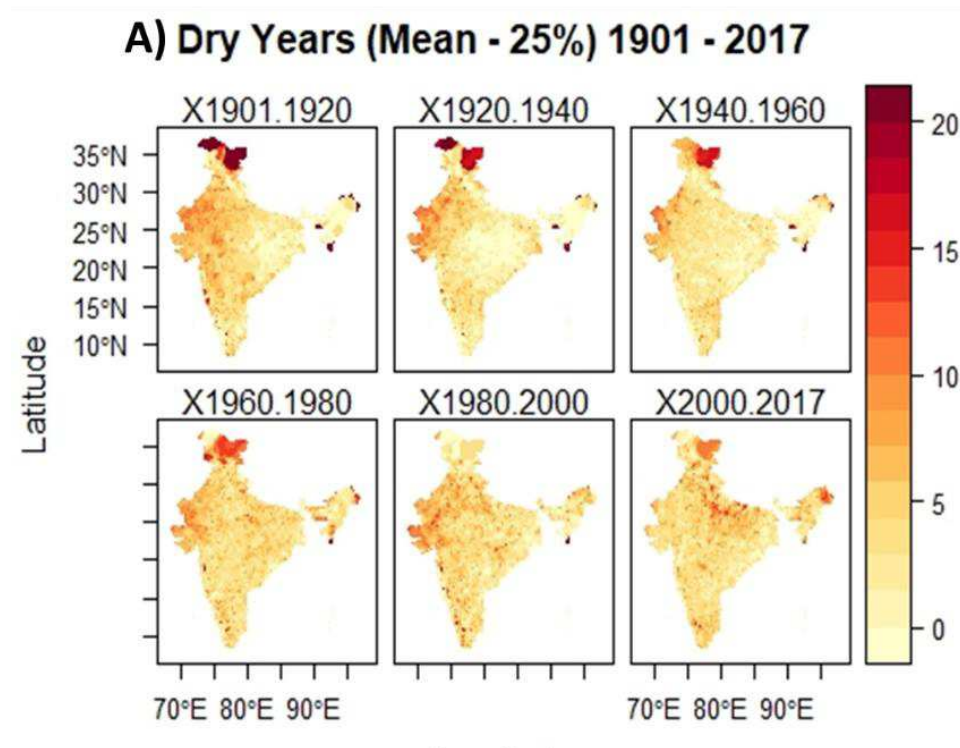

Longitude

\section{B) Wet Years (Mean + 25\%) 1901 - 2017}

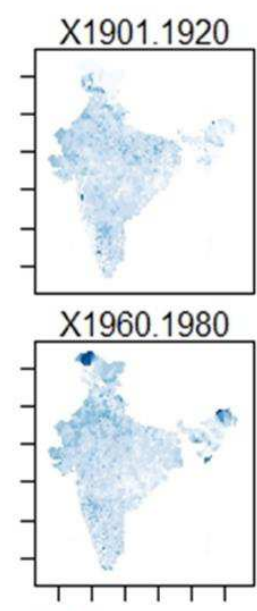

$70^{\circ} \mathrm{E} 80^{\circ} \mathrm{E} 90^{\circ} \mathrm{E}$

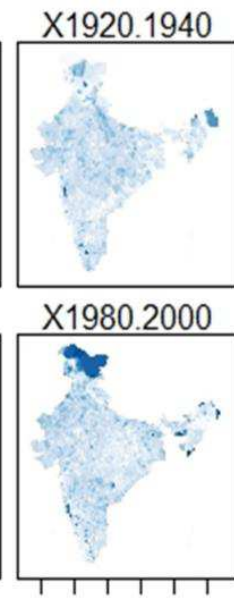

Longitude

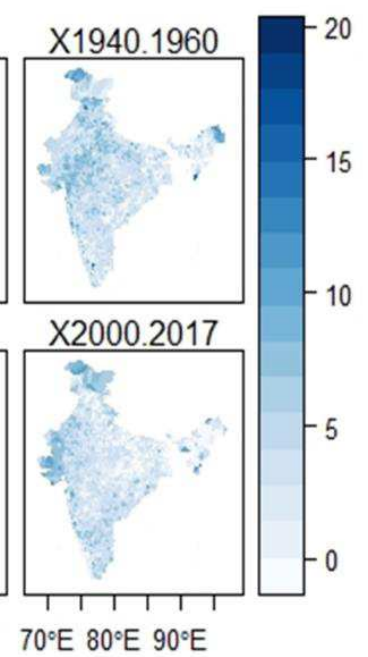

$70^{\circ} \mathrm{E} 80^{\circ} \mathrm{E} 90^{\circ} \mathrm{E}$

Fig 9: Vicennial Extreme Years Frequency Mapping. A) Dry years (<Mean- $25 \%)$ \& B) Wet years (<Mean $+25 \%)$

\subsubsection{Extreme Rainfall Events:}

Unlike other parameters, extreme rainfall events are direct observation of anomalistic rainfall behaviour and they are difficult to comprehend with spatial variation unless we map 117 maps for each year rainfall (even preparing the 117 maps can be incomprehensive). The events are defined based on Table 1 classification and the analyses of aggregated occurrences of these events show an interesting trend. The plots in Fig 10 show that although the high rainfall events (> $65 \mathrm{~mm}$ /day) have increased from the 1900s to 1950 s but have been stable for years thereafter, whereas the very high rainfall events (>100 mm/day) have been increasing after the 1970s. (MK Test: Tau $=0.343$, Two-sided $p$-value $<<$ 0.05) This observation, coupled with decreasing rainfall trends in many parts of India, indicates that the rainfall is more concentrated and happening in higher hails than evenly spread showers throughout the monsoon season. 

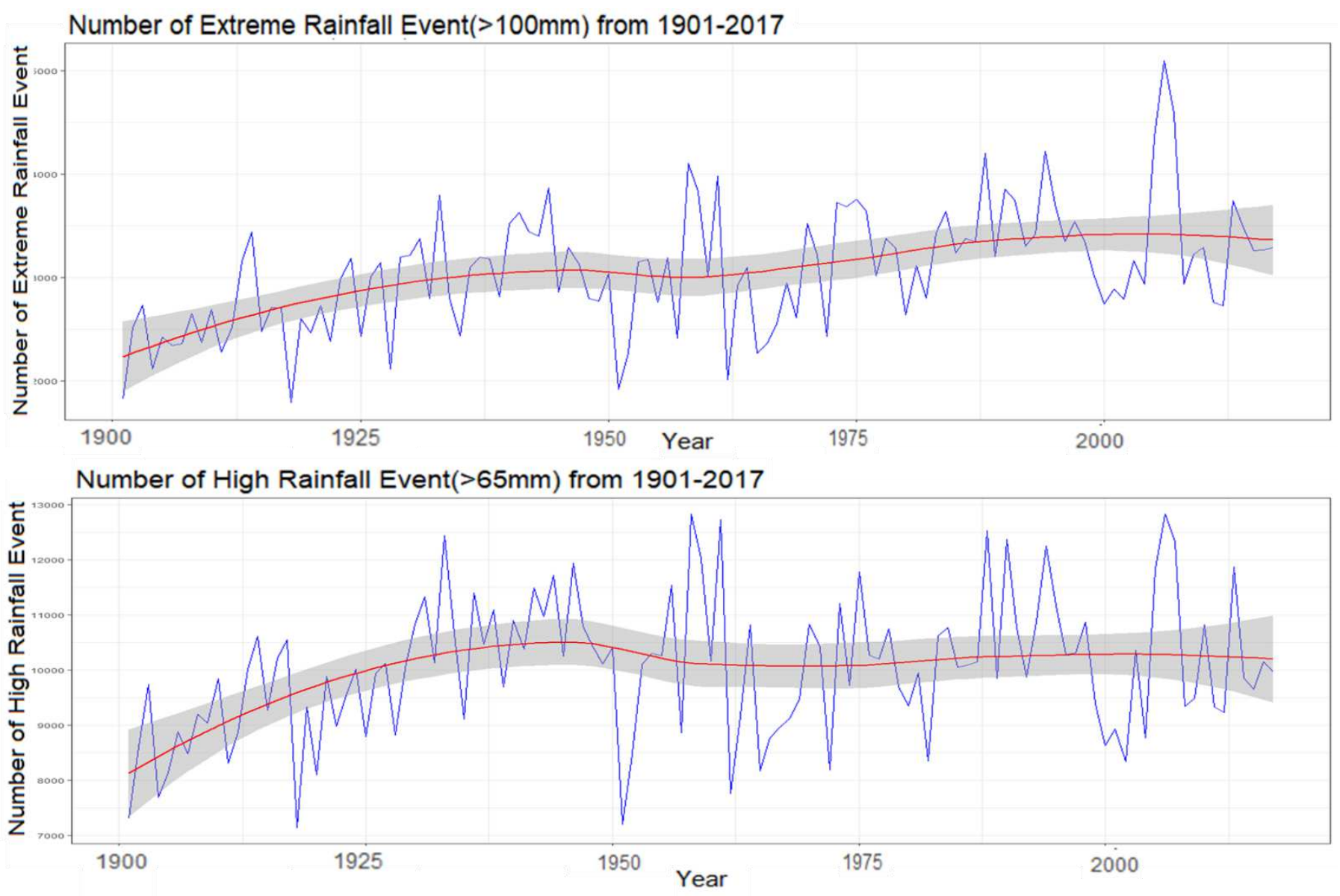

Fig 10: Number of Incidences with very high rainfall events. A) more than $65 \mathrm{~mm}$ Rainfall in 24 hours, B) more than $100 \mathrm{~mm}$ Rainfall in 24 hours. Red Line is the LOESS Regression Line (the smoothed trend line, Appendix 1).

\section{Understanding the Implications of the Observed Changes}

India is already facing large $\&$ diverse water-related challenges ranging from access to quality. One of the maximum impacts that can arise from the changing rainfall is the availability of freshwater and the vulnerability of agriculture as well as livelihood well-being. Discussing the socio-economic implications of the observed rainfall characteristics in entirety are beyond the scope of this section and the paper and can be a pioneer for further studies based on the results of this analysis. This section shall nudge start the process by briefly hammering on the broader implication of observed rainfall trends in different parts of India. Before we directly link the analyses results with the Indian social context, we need to quickly understand the spatial variability on a few key developmental, and factors of climate resilience. Fig 11 shows two very important livelihood related indicators that we will consider in this paper as a proxy to understand the vulnerability to rainfall change of different Indian regions; (A) Status of irrigation across India \& (B) A composite livelihood index highlighting the regions deprived on key developmental parameters. Access to irrigation is an important factor for agrarian and livelihood sustenance as it absorbs the negative impacts of the rainfall variability 
shock such as the climatic changes thus it is used as a proxy of the overall vulnerability of the population in different

parts of India along with percent rainfed area (complementing the irrigated area).

Quantum of rainfall and rainy days trend analyses in sections 3 indicates the northern parts of India majorly comprising of the states such as Eastern Uttar Pradesh, Bihar, West Bengal, Jharkhand, and Orissa that have seen adverse rainfall conditions (See Fig 5-6). These are the states that count for more than 40 percent population of India, and an estimated 70 percent of people live on agriculture and allied activities with major populations following substantial agriculture practices. The stark reality is further revealed in Fig 11 (B) that shows the region in yellow and red is a higher priority for livelihood-related interventions due to prevalent poverty and livelihood challenges. The changing rainfall and decreasing water availability shall hamper the already stressed regions of central and northern India. Also, these regions are worst prepared too. The regions are also the ones that are having the least human development index score in India and lack adequate resources to cope up with the risks associated with the changing normality of rainfall.

Decreasing quantum of rainfall and changing rainy days, monsoonal patterns are catastrophic for the agrarian wellbeing of the rainfed regions. Irrigation that is a very basic deterrent against falling water availability through rainfall is not adequate and lowest in the regions (except the state of Uttar Pradesh) with the most significant adverse rainfall changes. The changes are also detrimental for the irrigated regions with a lack of irrigation sustainability such as the State of Uttar Pradesh, Haryana, Punjab, etc. The abrupt rainfall events and shrinking rainy-days are detrimental for the groundwater irrigated pockets as the abnormal rainfall events will lead to more surface run-off/less recharge on top of further augmented groundwater extraction. India is already undergoing heavy groundwater stress, and the adverse climatic condition will prove further detrimental. Although India is currently the world's highest groundwater extractor, still there is potential to further develop the groundwater resources for quick and reliable water resources against the adverse climatic conditions in the regions with less groundwater development. Due to less groundwater development and less groundwater exploitation in the north and eastern part of India (highlighted earlier in the section for increasing threats of water security) (also see Fig $12(A)$ ), developing groundwater irrigation can potentially lead a way for resilience against changing rainfall patterns. But groundwater irrigation has a direct correlation with the accessibility of energy for irrigation. Unfortunately, the regions experiencing the rainfall changes are also the ones with the highest energy cost for irrigation (coloured in Yellow in Fig 12). There is an urgent need to make irrigation more accessible so that the impacts of variability in the rainfall can be mitigated. Also it is tested hypothesis that the 
and rainfall volatility.(Patel, Saha and Shah, 2020) Regions experiencing the better quantum of rainfall but increased variability (Western and Peninsular Regions, see Fig 4,5,and 6) needs better managed aquifer recharge activities or of the extra downpour available periodically.
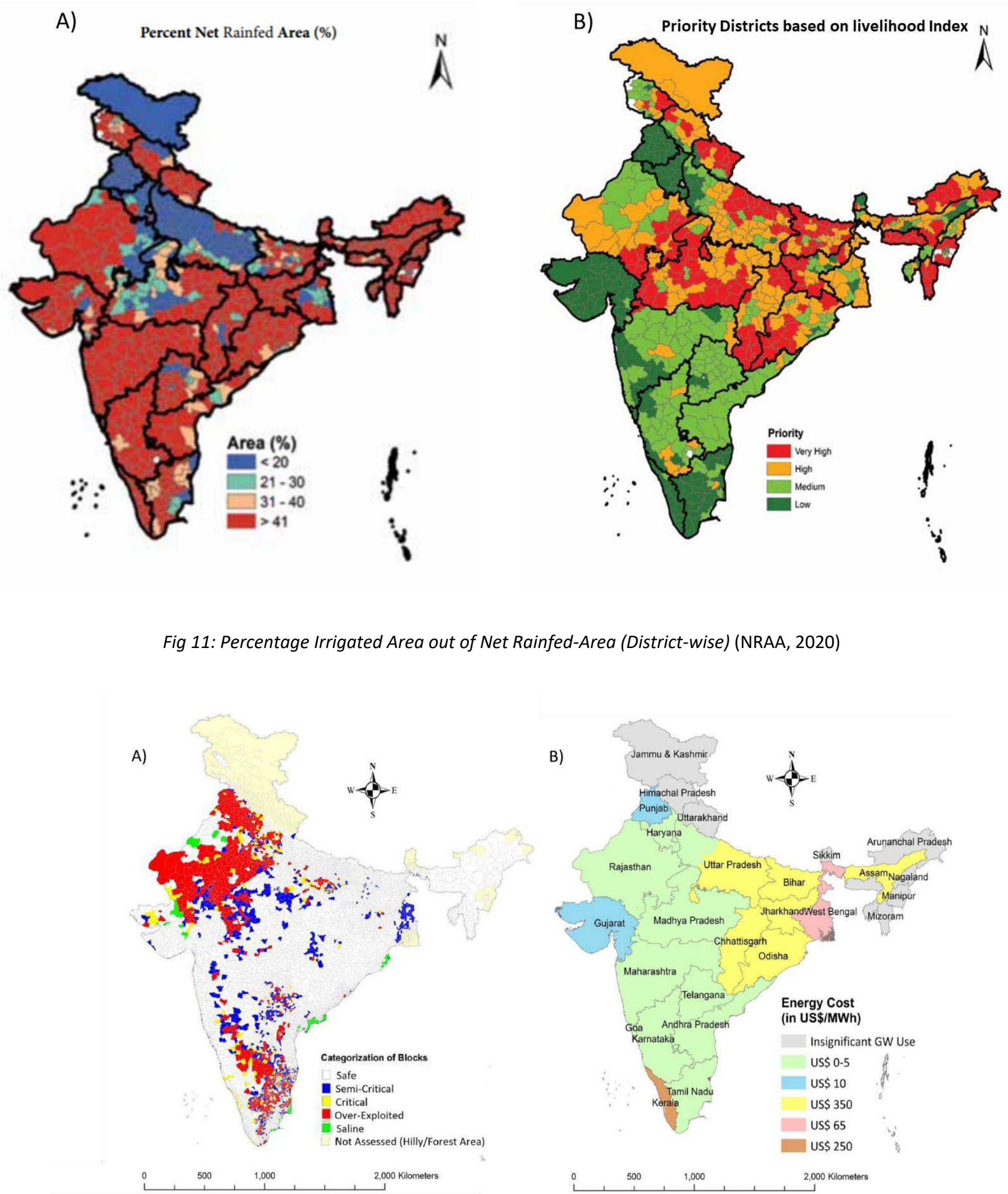

Fig 12: (A) Stage of Groundwater Development in India (B) Energy Cost of Irrigation (Rajan, Ghosh and Shah, 2020) 
The long-term and spatially elaborative analyses of key rainfall parameters confirm that the very threats discussed over years about the climate change and changing rainfall trends have already started and there have already been significant changes observed across spatial pockets in India. For India, the regions with significant adverse patterns are already vulnerable and if the observed trends continue then it may lead to large detrimental impacts for the sustenance of livelihood and well-being. The analyses validated that apart from changing the composition of rainfall distribution, the extreme rainfall events are increasing. This will lead to frequent flooding situations and create a huge burden for governments as well as society to cope-up with the losses.

The finer resolution data used here helped with understanding the data and trends for productively and further emphasized that the meteorological parameters analyzed as locally as possible can provide a better understanding of the impacts of climate change. The study is evocative of strong significant trends for regions that normally did not get captured in the sub-division level studies. There are significant decreasing rainfall trends in multiple pockets since 1970 which may supersede the increasing trends observed in minor pockets. The simultaneous analysis of pre- and post1970 data indicated the adverse trend observed spatially since the 1970s are were not existent before the 1970s and thus they are not naturally occurring phenomena. These are signs of anthropogenic environmental impacts changing the long-term normal climatic conditions.

The analysis of spatiotemporal rainfall parameters is crucial in several fields like water resource management, sustainable planning agriculture, ecosystem management, and the health sector. This analysis will help to distinguish vulnerable zones so that better water management decisions such as storage and irrigation infrastructure, cropping choices, and water security policies for sustainable land and water resources management can be implemented. The paper can pioneer the diverse discussions on the socio-economic implication of the changing rainfall patterns in India. Also, the methodology for trend analysis used here can be utilized for data available at further microscale such as at the village level for the planning of the developmental work. Developmental strategies can be re-evaluated considering changing rainfall patterns, reassessing the vulnerability of regions, and building up resources to mitigate the risk. There is still a scope to include further rainfall parameters that can help understand in anomalies in rainfall, wet spells, and dry spells distribution within monsoon season. This shall help in capturing the crucial moments of rainfall, such as 
adversely affects the agriculture and livelihood. It will enable better planning for sustainable development and disaster

431 risk reduction.

\section{$6 \underline{\text { Reference }}$}

Anand, B. and Karunanidhi, D. (2020) ‘Long term spatial and temporal rainfall trend analysis using GIS and statistical methods in Lower Bhavani basin, Tamil Nadu, India', Indian Journal of Geo-Marine Sciences, 49(3), pp. 419-427.

Dash, S. K. et al. (2007) 'Some evidence of climate change in twentieth-century India', Climatic Change, 85(3-4), pp. 299-321. doi: 10.1007/s10584-007-9305-9.

Douglas, E. M., Vogel, R. M. and Kroll, C. N. (2000) 'Trends in floods and low flows in the United States: Impact of spatial correlation', Journal of Hydrology, 240(1-2), pp. 90-105. doi: 10.1016/S0022-1694(00)00336-X.

Dube, R. and Rao, G. (2005) 'Extreme Weather Events over India in the last 100 years', J. Indian Geophys. Union, 9. Economic Survey (no date). Available at: https://www.indiabudget.gov.in/economicsurvey/ (Accessed: 16 October 2020).

FAO (2016) Agricultural irrigated land (\% of total agricultural land), Data.Worldbank.org. Available at: https://data.worldbank.org/indicator/AG.LND.IRIG.AG.ZS (Accessed: 31 August 2020).

Gosain, A. K., Rao, S. and Basuray, D. (2006) 'Climate change impact assessment on hydrology of Indian river basins', Current Science, 90(3), pp. 346-353.

Goswami, B. N. et al. (2006) 'Increasing trend of extreme rain events over India in a warming environment', Science, 314(5804), pp. 1442-1445. doi: 10.1126/science.1132027.

Jaiswal, R. K., Lohani, A. K. and Tiwari, H. L. (2015) 'Statistical Analysis for Change Detection and Trend Assessment in Climatological Parameters', Environmental Processes, 2(4), pp. 729-749. doi: 10.1007/s40710-015-0105-3.

Javari, M. (2016) 'Trend and homogeneity analysis of precipitation in Iran', Climate, 4(3), p. 44. doi: 10.3390/cli4030044.

John, S. K. (2018) 'Rainfall Pattern Analysis over India in Relation to the State of Kerala', in Engineering and Mathematical Topics in Rainfall. InTech. doi: 10.5772/intechopen.72870. 
Khan, T. M. A., Singh, O. P. and Rahman, M. S. (2000) 'Recent sea level and sea surface temperature trends along the bangladesh coast in relation to the frequency of intense cyclones', Marine Geodesy, 23(2), pp. 103-116. doi: 10.1080/01490410050030670.

Köppen, W. (1918) 'Klassifikation der Klimate nach Temperatur, Niederschlag und Jahresablauf (Classification of climates according to temperature, precipitation and seasonal cycle)', Petermanns Geogr. Mitt., 64(Sept-Oct), pp. 193-203.

Kumar, V., Jain, S. K. and Singh, Y. (2010) 'Analysis of long-term rainfall trends in India', Hydrological Sciences JournalJournal des Sciences Hydrologiques, 55(4), pp. 484-496. doi: 10.1080/02626667.2010.481373.

Lal New Delhi (India)], M. [Indian I. of T. (2003) ‘Global climate change. India's monsoon and its variability’.

Mondal, A., Khare, D. and Kundu, S. (2014) 'Spatial and temporal analysis of rainfall and temperature trend of India', Theoretical and Applied Climatology, 122, pp. 143-158. doi: 10.1007/s00704-014-1283-z.

Mondal, A., Khare, D. and Kundu, S. (2015) 'Spatial and temporal analysis of rainfall and temperature trend of India', Theoretical and Applied Climatology, 122(1-2), pp. 143-158. doi: 10.1007/s00704-014-1283-z.

Monirul Qader Mirza, M. (2002) 'Global warming and changes in the probability of occurrence of floods in Bangladesh and implications', Global Environmental Change, 12(2), pp. 127-138. doi: 10.1016/S09593780(02)00002-X. Nandargi, S. S. and Gupta, V. K. (2018) 'Spatial and Temporal Distribution of Rainfall and Rainy Days over the Goa State', 1(1), pp. 1-17.

NRAA (2020) Prioritization of Districts for Development Planning in India A Composite Index Approach. New Delhi. Available at: http://nraa.gov.in/Interface/Data/Prioritization of Districts for Development Planning in India A Composite Index Approach.pdf.

others Solomon, Susan and Manning, Martin and Marquis, Melinda and Qin, D. (2007) Climate change 2007-the physical science basis: Working group I contribution to the fourth assessment report of the IPCCtle. Cambridge university press.

Pai, D. S. et al. (2014) Development of a new high spatial resolution $\left(0.25^{\circ} \times 0.25^{\circ}\right)$ long period (1901-2010) daily gridded rainfall data set over India and its comparison with existing data sets over the region, undefined. 
Panda, A. and Sahu, N. (2019) 'Trend analysis of seasonal rainfall and temperature pattern in Kalahandi, Bolangir and

Koraput districts of Odisha, India', Atmospheric Science Letters, 20(10). doi: 10.1002/asl.932.

Partal, T. and Kahya, E. (2006) 'Trend analysis in Turkish precipitation data', Hydrological Processes, 20(9), pp. 20112026. doi: 10.1002/hyp.5993.

Patakamuri, S. K., Muthiah, K. and Sridhar, V. (2020) 'Long-Term homogeneity, trend, and change-point analysis of rainfall in the arid district of ananthapuramu, Andhra Pradesh State, India', Water (Switzerland), 12(1). doi: 10.3390/w12010211.

Patel, P. M., Saha, D. and Shah, T. (2020) 'Sustainability of groundwater through community-driven distributed recharge: An analysis of arguments for water scarce regions of semi-arid India', Journal of Hydrology: Regional Studies, 29. doi: 10.1016/j.ejrh.2020.100680.

Pettitt, A. N. (1979) 'A Non-Parametric Approach to the Change-Point Problem', Applied Statistics, 28(2), p. 126. doi: $10.2307 / 2346729$.

Praveen, B. et al. (2020a) 'Analyzing trend and forecasting of rainfall changes in India using non-parametrical and machine learning approaches', Scientific Reports, 10(1), pp. 1-21. doi: 10.1038/s41598-020-67228-7.

Praveen, B. et al. (2020b) 'Analyzing trend and forecasting of rainfall changes in India using non-parametrical and machine learning approaches', Scientific Reports, 10(1), pp. 1-21. doi: 10.1038/s41598-020-67228-7.

Rajan, A., Ghosh, K. and Shah, A. (2020) 'Carbon footprint of India's groundwater irrigation', Carbon Management, 11(3), pp. 265-280. doi: 10.1080/17583004.2020.1750265.

Reyer, C. P. O. et al. (2017) 'Turn down the heat: regional climate change impacts on development', Regional Environmental Change. Springer Verlag, pp. 1563-1568. doi: 10.1007/s10113-017-1187-4.

Sen, P. K. (1968) 'Estimates of the Regression Coefficient Based on Kendall's Tau', Journal of the American Statistical Association, 63(324), pp. 1379-1389. doi: 10.1080/01621459.1968.10480934.

Shrestha, A. B. et al. (2000) 'Precipitation fluctuations in the Nepal Himalaya and its vicinity and relationship with some large scale climatological parameters', International Journal of Climatology, 20(3), pp. 317-327. doi: 10.1002/(SICI)1097-0088(20000315)20:3<317::AID-JOC476>3.0.CO;2-G. 
T H, U., BM, S. and M., M. (2016) 'Impact of Climate Change on Rainfall Pattern and Reservoir Level', Journal of Water Resource Engineering and Management, 3, pp. 10-14.

Taxak, A. K., Murumkar, A. R. and Arya, D. S. (2014) 'Long term spatial and temporal rainfall trends and homogeneity analysis in Wainganga basin, Central India', Weather and Climate Extremes, 4, pp. 50-61. doi: 10.1016/j.wace.2014.04.005.

The World Bank (2012) Turn Down the Heat: Why a $4^{\circ} \mathrm{C}$ Warmer World Must Be Avoided - Executive Summary. Washington, DC. Available at: www.worldbank.org (Accessed: 31 August 2020).

Varikoden, H. and Revadekar, J. V. (2019) 'On the extreme rainfall events during the southwest monsoon season in northeast regions of the Indian subcontinent', Meteorological Applications, 27(1). doi: 10.1002/met.1822.

Wallemacq, P., UNISDR and CRED (2018) ‘Economic Losses, Poverty and Disasters 1998-2017’. doi: 10.13140/RG.2.2.35610.08643.

Yu, Y. S., Zou, S. and Whittemore, D. (1993) 'Non-parametric trend analysis of water quality data of rivers in Kansas', Journal of Hydrology, 150(1), pp. 61-80. doi: 10.1016/0022-1694(93)90156-4.

Yue, S. and Hashino, M. (2003) 'Temperature trends in Japan: 1900-1996', Theoretical and Applied Climatology, 75(1-2), pp. 15-27. doi: 10.1007/s00704-002-0717-1.

Zhou, T. et al. (2009) 'Why the Western Pacific Subtropical High Has Extended Westward since the Late 1970s', Journal of Climate, 22(8), pp. 2199-2215. doi: 10.1175/2008JCLI2527.1.

\section{Annexure: 1}

\section{Pettitt's Test:}

The Pettitt test is a distribution-free rank-based test, used to discover noteworthy changes in the mean of the time series. It is more helpful when hypothesis testing about the location of a change point is not necessary. This test has been used extensively to identify the changes observed in climatic and hydrological data series 87,88 . When the length of a time series is represented by $t$ and the shift takes place at $m$ years, the consequential 
test statistics are expressed as given in Eqn. (i). The statistic is similar to the Mann- Whitney statistic, which

$$
U_{t, m}=\sum_{i=1}^{m} \sum_{j=t+1}^{t} \operatorname{sgn}\left(K_{i}-K_{j}\right)
$$

where sgn in Eqn. $\mathrm{i}$ is defined by Eqn. ii

$$
\operatorname{sgn}\left(K_{i}-K_{j}\right)=\left(\begin{array}{ccc}
1 & \text { if }\left(K_{i}-K_{j}\right) & \rangle 1 \\
0 & \text { if }\left(K_{i}-K_{j}\right) & =0 \\
-1 & \text { if }\left(K_{i}-K_{j}\right) & \langle 1
\end{array}\right)
$$

The test statistic $U_{t, m}$ is calculated from all haphazard variables from 1 to $n$. The majority of distinctive change points

$$
Z_{T}=\operatorname{Max}_{1 \leq t(m)}\left|U_{t . m}\right|
$$

The probability of shifting year is estimated when $\left|U_{t, m}\right|$ is maximum following Eqn. iv

$$
P=1-\exp \left(\frac{-6 Z_{T}^{2}}{K^{2}+K^{3}}\right)
$$

539 If the $p$-value is less than the significance level $\alpha$, the null hypothesis is considered to be rejected.

540 Mann Kendall Test: The MK test tests whether to reject the null hypothesis $\left(\mathrm{H}_{0}\right)$ and accept the alternative hypothesis

$541\left(H_{a}\right)$, where

$\mathrm{H}_{0}$ : No monotonic trend

$\mathrm{H}_{\mathrm{a}}$ : Monotonic trend is present

The initial assumption of the MK test is that the $\mathrm{H}_{0}$ is true and that the data must be convincing beyond a reasonable 545 doubt before $\mathrm{H}_{0}$ is rejected and $\mathrm{Ha}$ is accepted. 
547 1. List the data in the order in which they were collected over time $x_{1}, x_{2}, \ldots, x_{n}$, which denote the measurements

548 obtained at times $1,2, \ldots, n$, respectively.

549 2. Determine the sign of all $n(n-1) / 2$ possible differences $x_{j}-x_{k}$, where $j>k$. These differences are $550 \quad x_{2}-x_{1}, x_{3}-x_{1}, \ldots, x_{n}-x_{1}, x_{3}-x_{2}, x_{4}-x_{2}, \ldots, x_{n}-x_{n-2}, x_{n}-\left(x_{n-1}\right)$

551 3. Let $\operatorname{sgn}\left(x_{j}-x_{k}\right)$ be an indicator function that takes on the values 1,0 , or -1 according to the sign of $x_{j}-x_{k}$, that is, $\operatorname{sgn}\left(x_{j}-x_{k}\right)=1$ if $x_{j}-x_{k}>0$

$=0$ if $x_{j}-x_{k}=0$, or if the sign of $x_{j}-x_{k}$ cannot be

determined due to non-detects

$$
=-1 \text { if } x_{j}-x_{k}<0
$$

552 or example, if $x_{j}-x_{k}>0$, that means that the observation at time $j$, denoted

553 by $x_{k}$, is greater than the observation at time $k$, denoted by $x_{k}$.

554 4. Compute

$S=\sum k-1 n-1 \sum j-k+1 n s g n\left(x_{j}-x_{k}\right)(1)$

556 which is the number of positive differences minus the number of negative differences. If $S$ is a positive number, 557 observations obtained later in time tend to be larger than observations made earlier. If $\mathrm{S}$ is a negative number, then observations made later in time tend to be smaller than observations made earlier.

559 5. If $n \leq 10$, follow the procedure described in Gilbert (1987, page 209, Section 16.4.1) by looking up $S$ in a table of probabilities (Gilbert 1987, Table A18, page 272). If this probability is less than $\alpha$ (the probability of 4 concluding a trend exists when there is none), then reject the null hypothesis and conclude the trend exists. If $\mathrm{n}$ cannot be found in the table of probabilities (which can happen if there are tied data values), the next value farther from zero in the table is used. For example, if $S=12$ and there is no value for $S=12$ in the table, it is handled the same as $S=13$.

564 If $n>10$, continue with steps 6 through 10 to determine whether a trend exists. This follows the procedure described 565 in Gilbert (1987, page 211, Section 16.4.2).

566 6. Compute the variance of S as follows: 
where $g$ is the number of tied groups and $t p$ is the number of observations in the $p^{\text {th }}$ group. For example, in the 569 sequence of measurements in time $\{23,24,29,6,29,24,24,29,23\}$ we have $g=3$ tied groups, for which $t_{1}=2$ for the 570 tied value $23, t_{2}=3$ for the tied value 24 , and $t_{3}=3$ for the tied value 29 . When there are ties in the data due to equal 571 values or non-detects, VAR(S) is adjusted by a tie correction method described in Helsel $(2005$, p. 191).

572 7. Compute the $M K$ test statistic, $Z_{M K}$, as follows:

$$
\begin{aligned}
& \mathrm{Z}_{\mathrm{MK}}=(S-1) / \sqrt{ } \operatorname{VAR}(S) \text {, if } \mathrm{S}>0 \\
& =0 \quad \text {, if } S=0 \\
& =(S+1) / \sqrt{ } \operatorname{VAR}(S), \text { if } \mathrm{S}<0
\end{aligned}
$$

A positive (negative) value of $Z_{M K}$ indicates that the data tend to increase

575 (decrease) with time.

$576 \quad$ 8. Suppose we want to test the null hypothesis

$577 \quad \mathrm{H}_{0}$ : No monotonic trend

578 versus the alternative hypothesis

$579 \quad \mathrm{H}_{\mathrm{a}}$ : Upward monotonic trend

580 at the Type I error rate $\alpha$, where $0<\alpha<0.5$. (Note that $\alpha$ is the tolerable probability that the MK test will falsely reject 581 the null hypothesis.) Then $H_{0}$ is rejected and $\mathrm{Ha}$ is accepted if $Z_{M K} \geq Z_{1-\alpha}$, where $Z_{1}-\alpha$ is the $100(1-\alpha)^{\text {th }}$ 582 percentile of the standard normal distribution. These percentiles are provided in 583 many statistics book (for example Gilbert 1987, Table A1, page 254) and 584 statistical software packages.

5859 9. To test $\mathrm{H}_{0}$ above versus

$\mathrm{H}_{\mathrm{a}}$ : Downward monotonic trend

587 at the Type I error rate $\alpha, H_{0}$ is rejected and $\mathrm{Ha}$ is accepted if $Z_{M K} \leq-Z_{1-\alpha}$. 
590 at the Type I error rate $\alpha, H_{0}$ is rejected and $\mathrm{Ha}$ is accepted if $\left|Z_{M K}\right| \geq Z_{1-\alpha / 2}$,

591 where the vertical bars denote absolute value.

592 Sen's Estimator: According to Hirsch et al. (1982) the seasonal Sen's slope is calculated as follows:

$593 \quad d_{i j k}=\frac{\left(X_{i j}-X_{j k}\right)}{j-k}$

594 for each $\left(x_{i j}, x_{i k}\right.$ pair $i=1,2, \ldots, m$, where $1 \leq k<j \leq n_{i}$ and $n_{i}$ is the number of known values in the $i^{\text {th }}$ season. The 595 seasonal slope estimator is the median of the $d_{\mathrm{ijk}}$ values.

\section{LOESS Regression:}

597 Locally weighted running smoother regression is a non-parametric smoother which has linear regression at its core.

598 (Jacoby, 2000) LOESS is commonly used for depicting the relationship between variables. The idea of LOESS is to 599 recover the inherent signal from the noisy sample. This algorithm estimates the value of the function by using 600 neighborhood sampled or known values.

601 For every point that we set to estimate $\left(x^{\prime}\right)$, the LOESS sets a linear regression model that calculates corresponding 602 output $\left(y^{\prime}\right)$ using the $k$ nearest neighbor of $x^{\prime}$ and sets a weight that rates their importance.

603 The distance weights are calculated using the tri-cubic function

$w(x)=\left\{\begin{array}{cc}\left(1-|x|^{3}\right)^{3} & |x|<1 \\ 0 & |x| \geq 1\end{array}\right.$ 
Figures

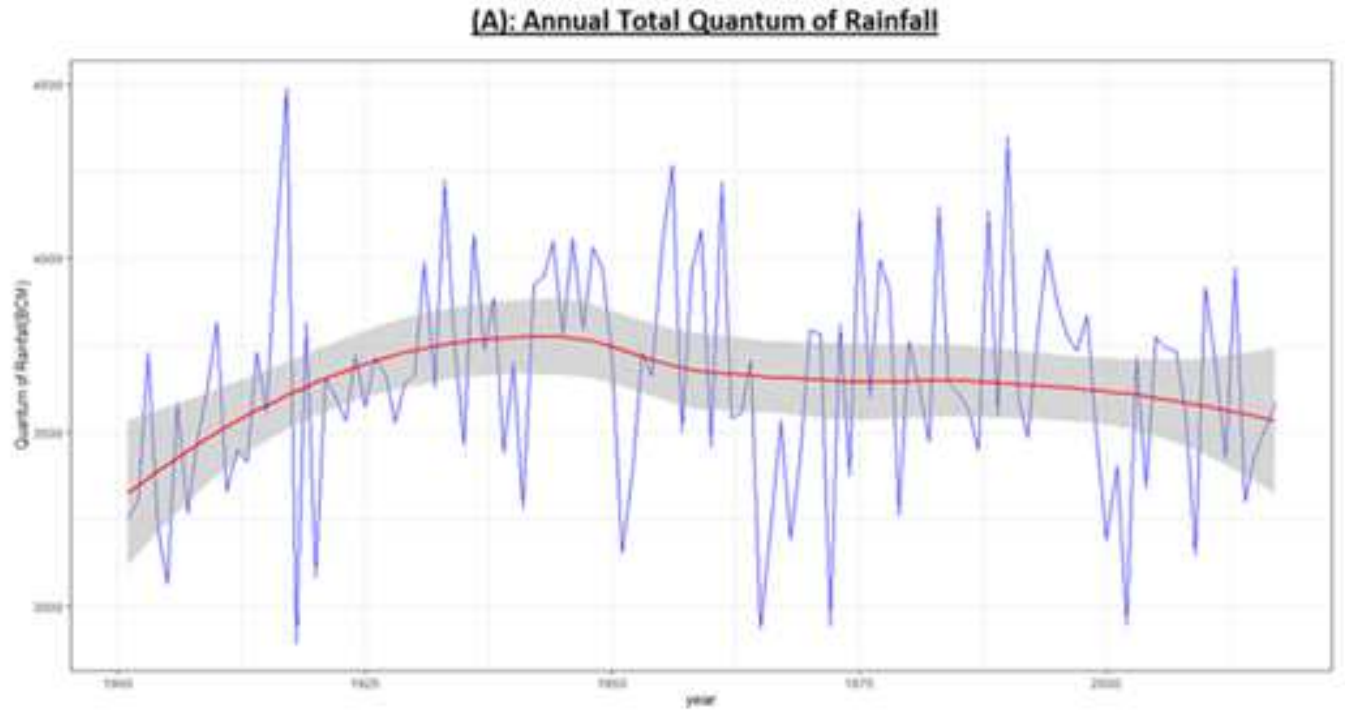

(B): Aggregated Annual and Monsoon Rainfall in India

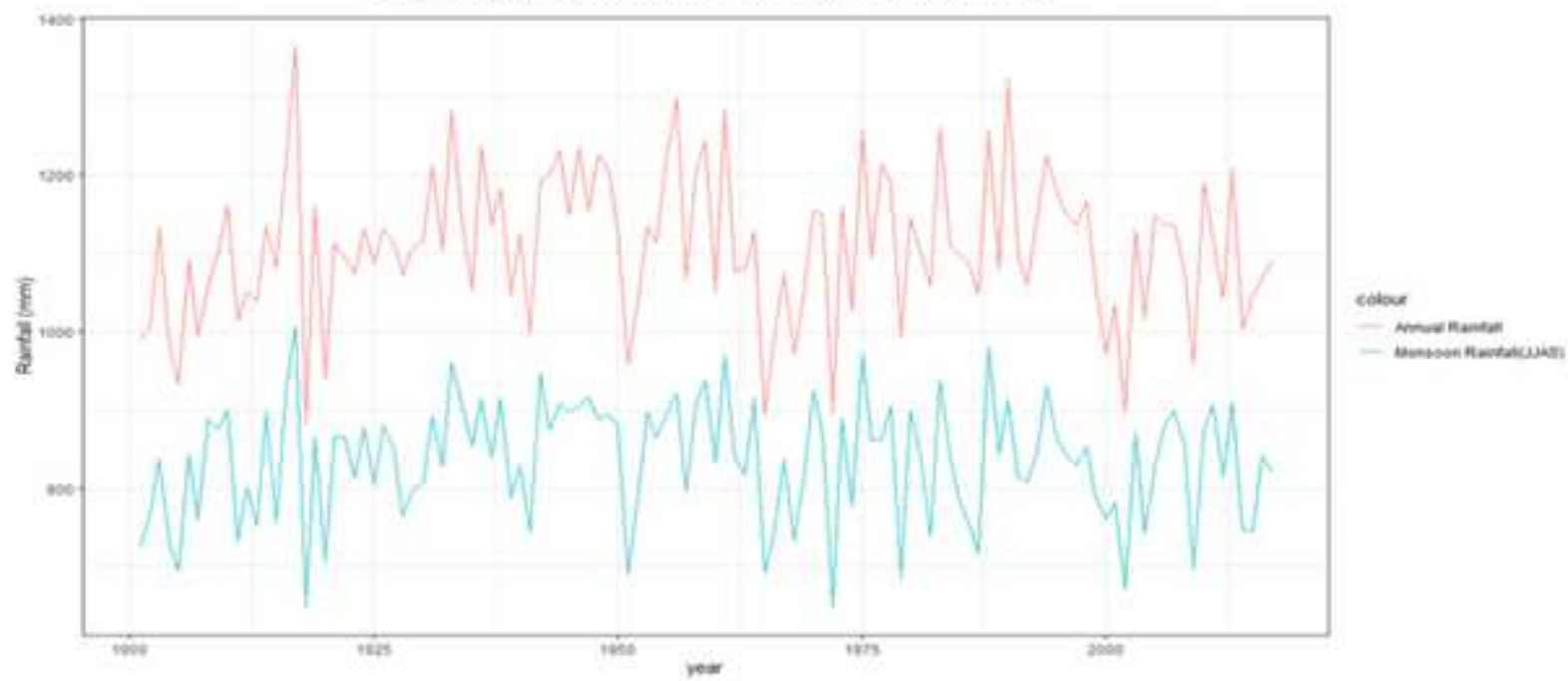

Figure 1

Observed Annual Rainfall (A) Total Estimated Volume of Rainfall (BCM) (B)Aggregated Annual Rainfall $(\mathrm{mm})$. 

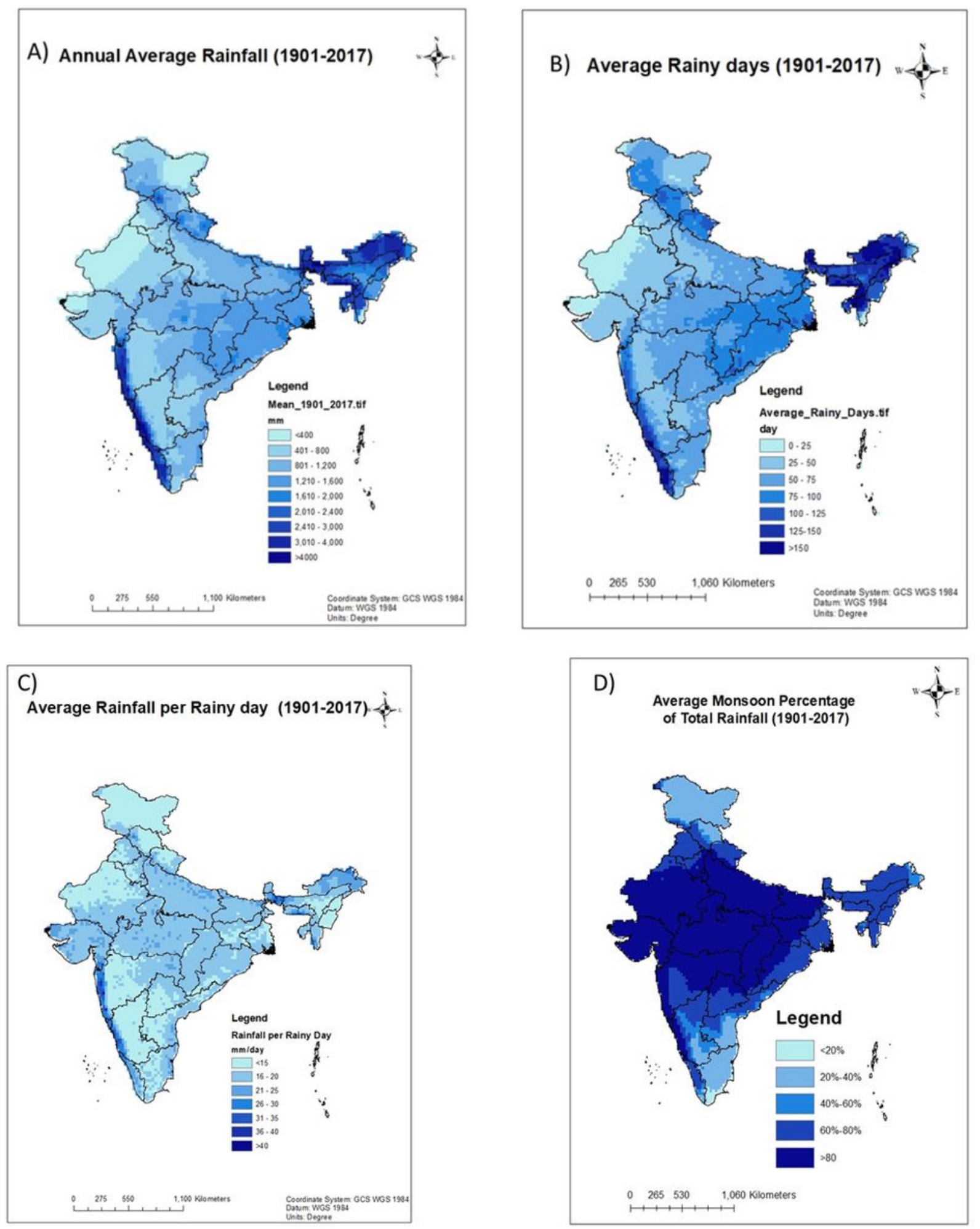

\section{Figure 2}

Annual Normal Rainfall A) Average of Quantum of Rainfall B) Normal Rainy-days C) Average rainfall per rainy-day D) Percentage of total Rainfall received within monsoon months of June-July-AugustSeptember (JJAS) 

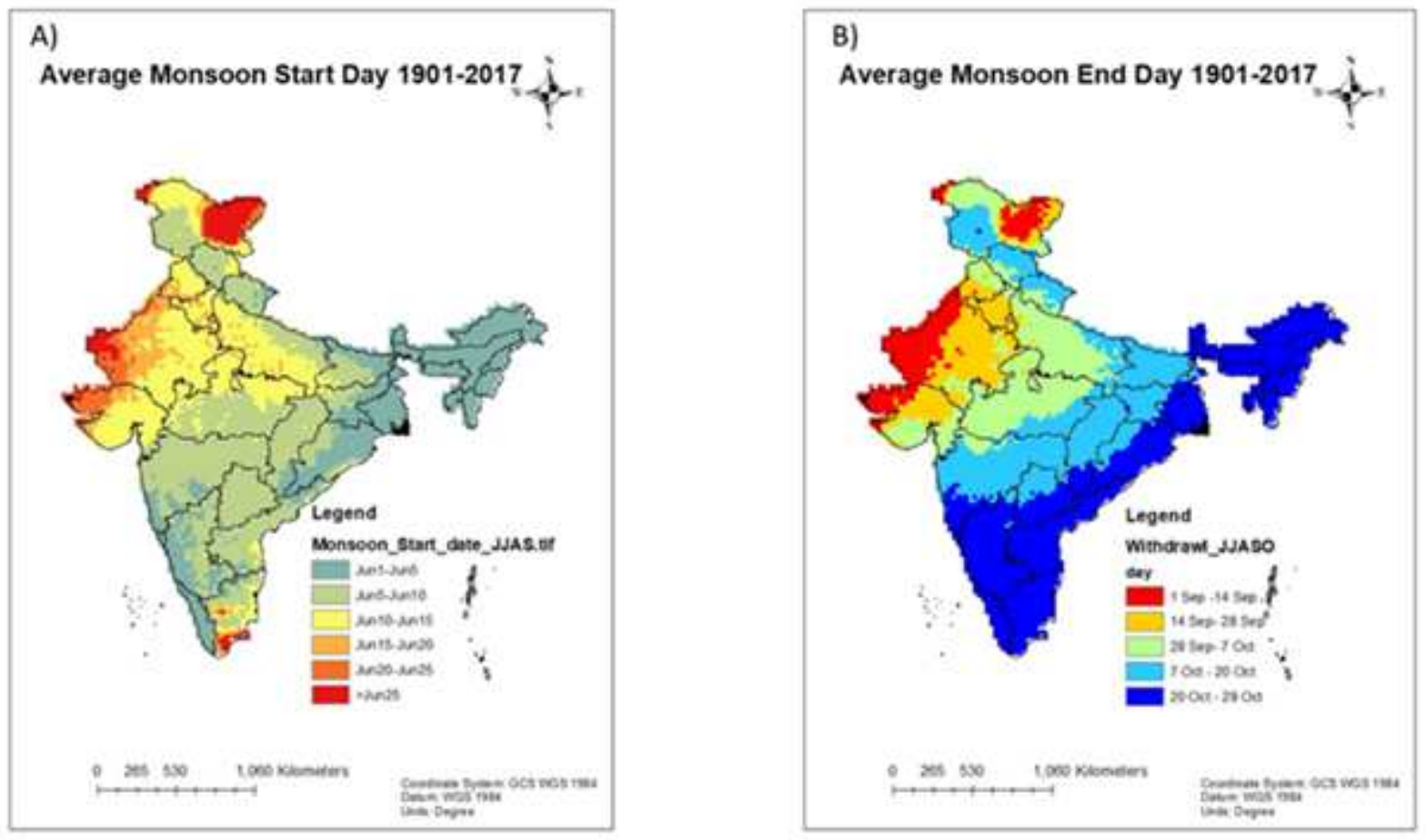

\section{Figure 3}

Normal (Average 1901-2017) onset (A) and withdrawal dates (B) in India.
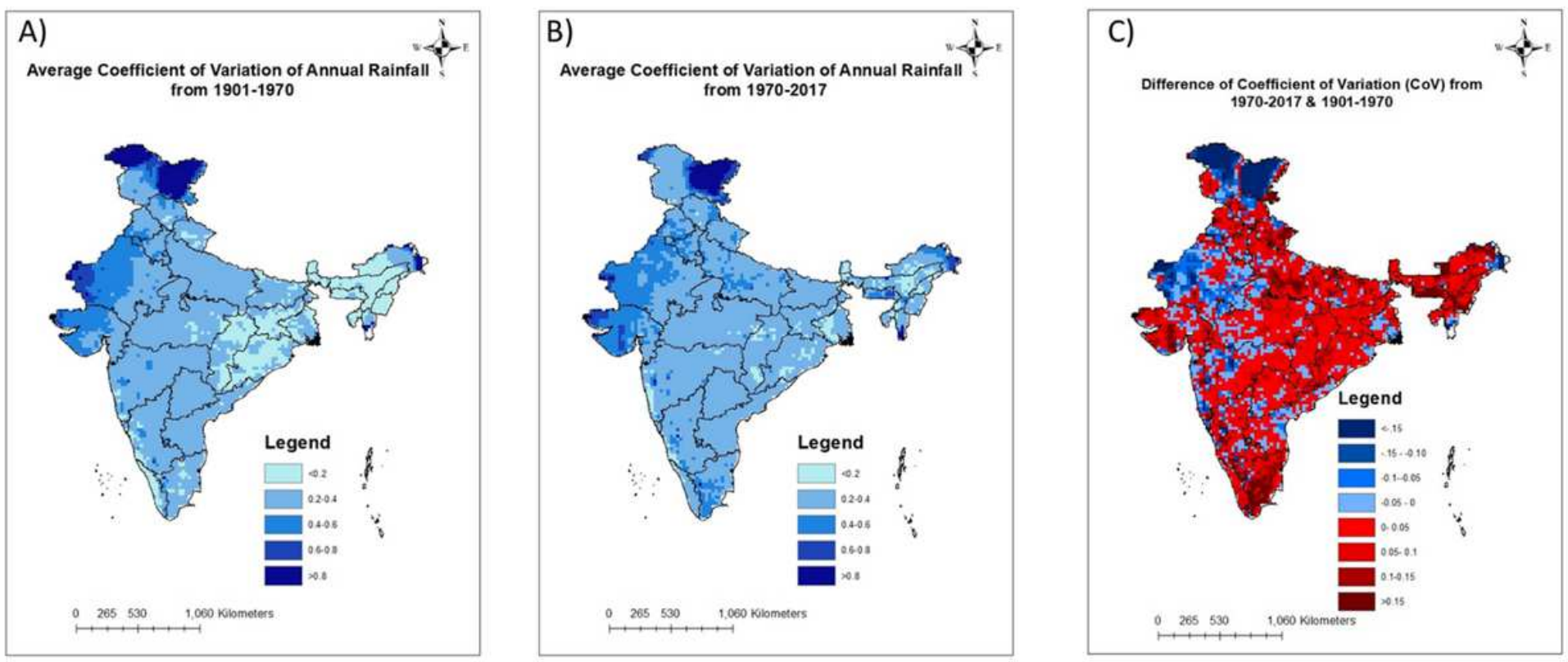

Figure 4

Coefficient of Variation (CV) of the quantum of Rainfall (A) before 1970, (B) after 1970, (c) difference in Coefficient of variation 1970-2017 vs 1901-1970 (Red: Increased variation, Blue: Reduced Variation). 

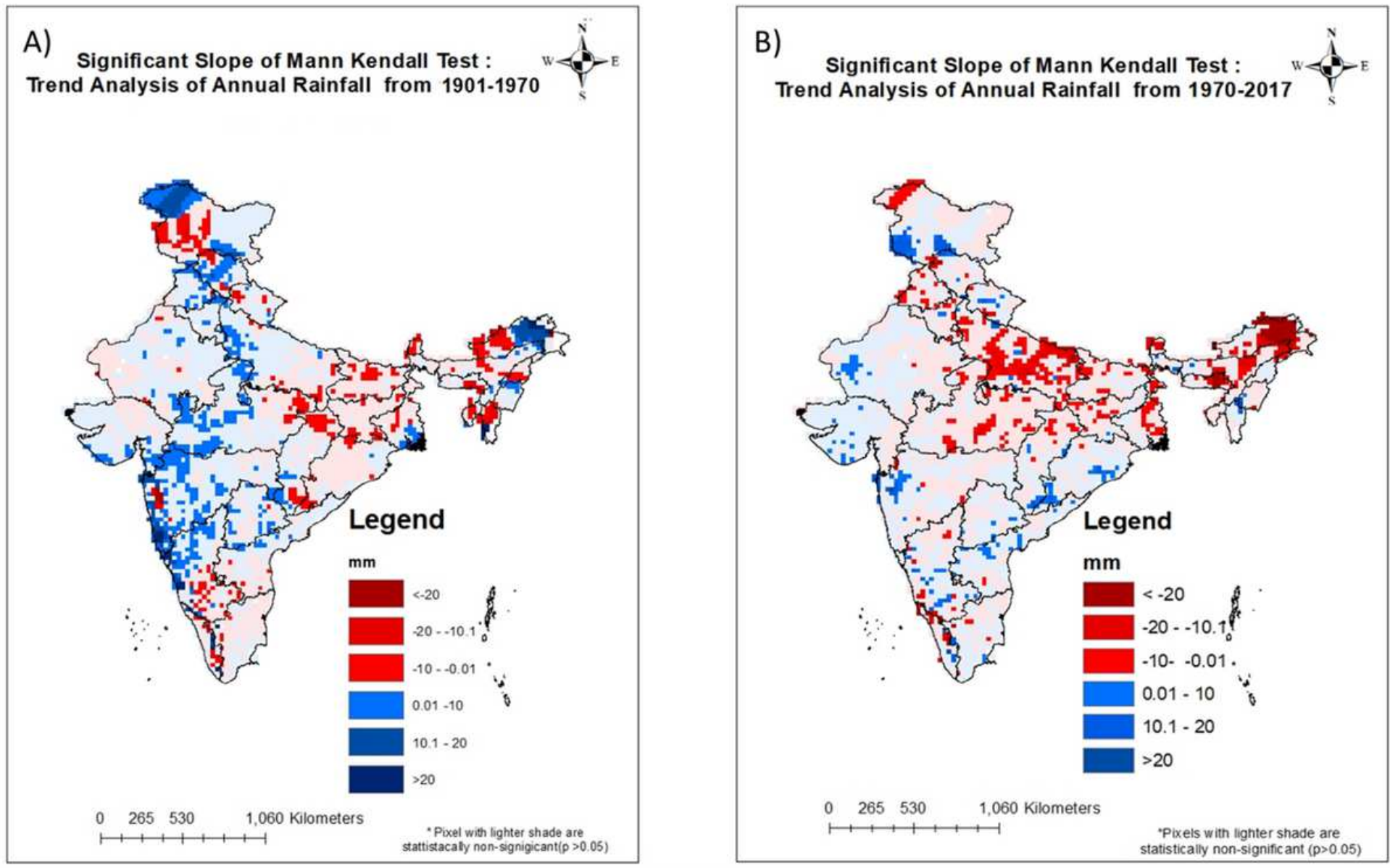

\section{Figure 5}

Quantum of Rainfall significant trend and Sen's Slope Estimates. A) 1901-1970 \& B)1970-2017
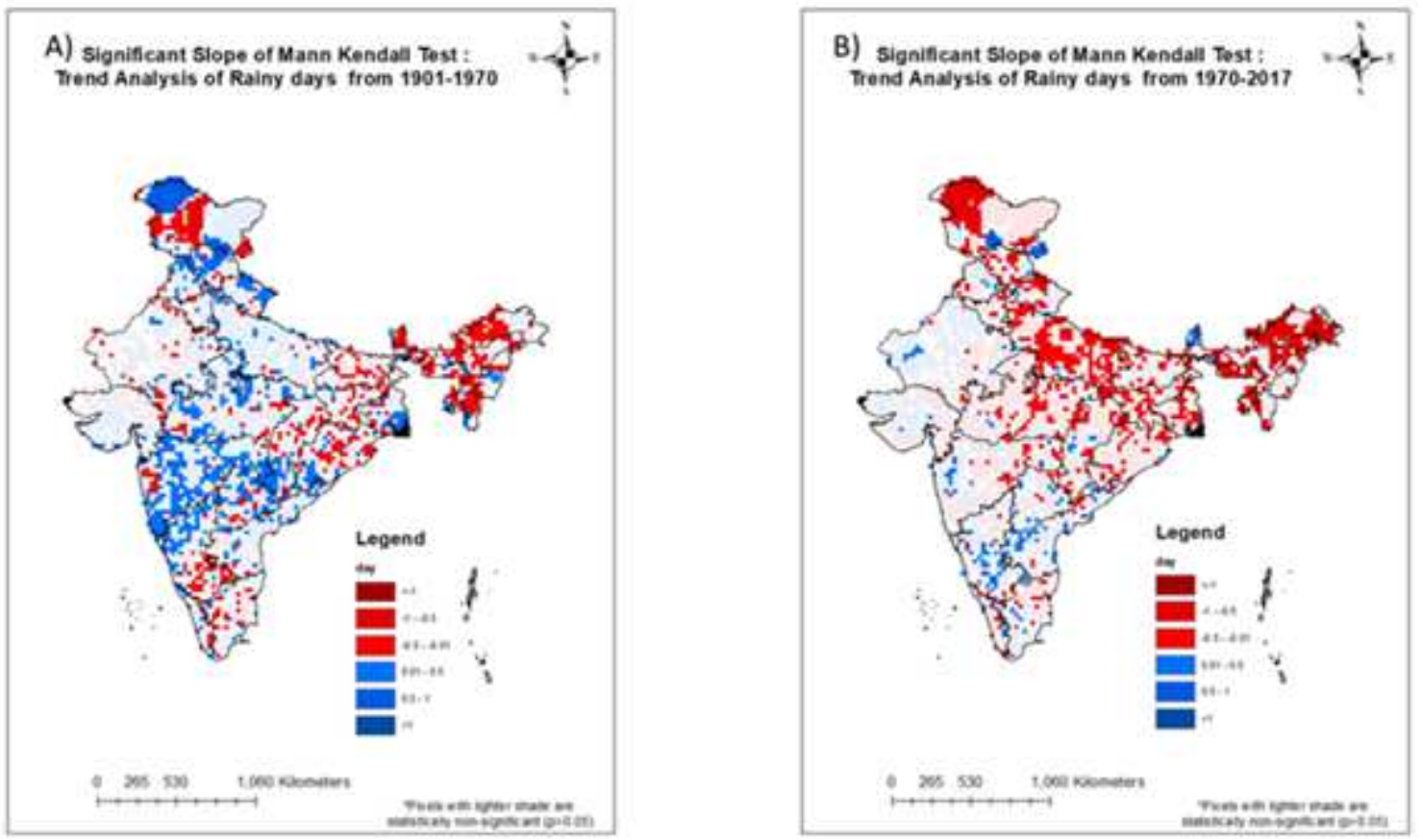

Figure 6 
Rainy-days significant trend and Sen's Slope Estimates. A) 1901-1970 \& B)1971-2017
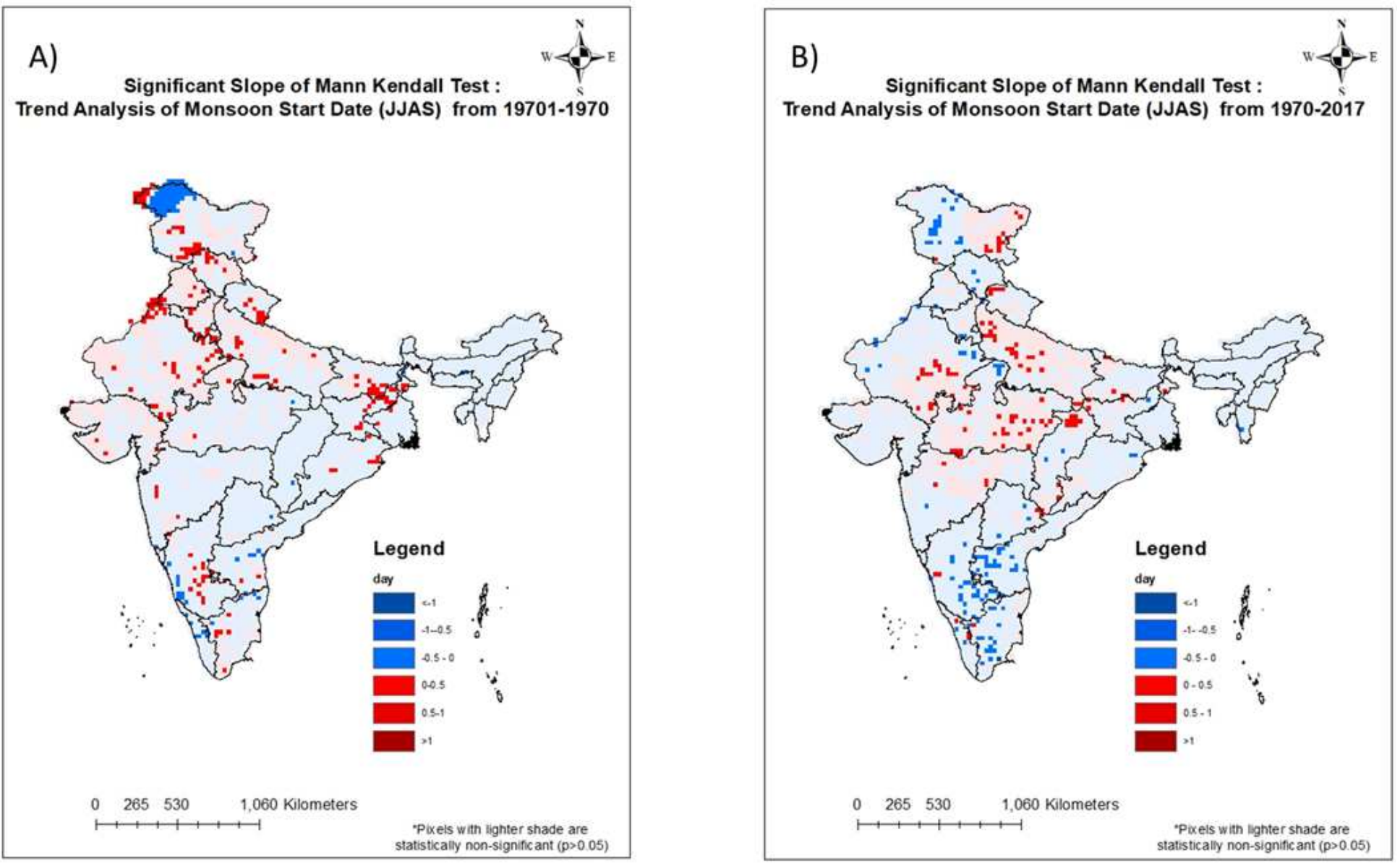

\section{Figure 7}

Onset of Monsoon significant trend and Sen's Slope Estimates. A) 1901-1970 \& B)1970-2017 

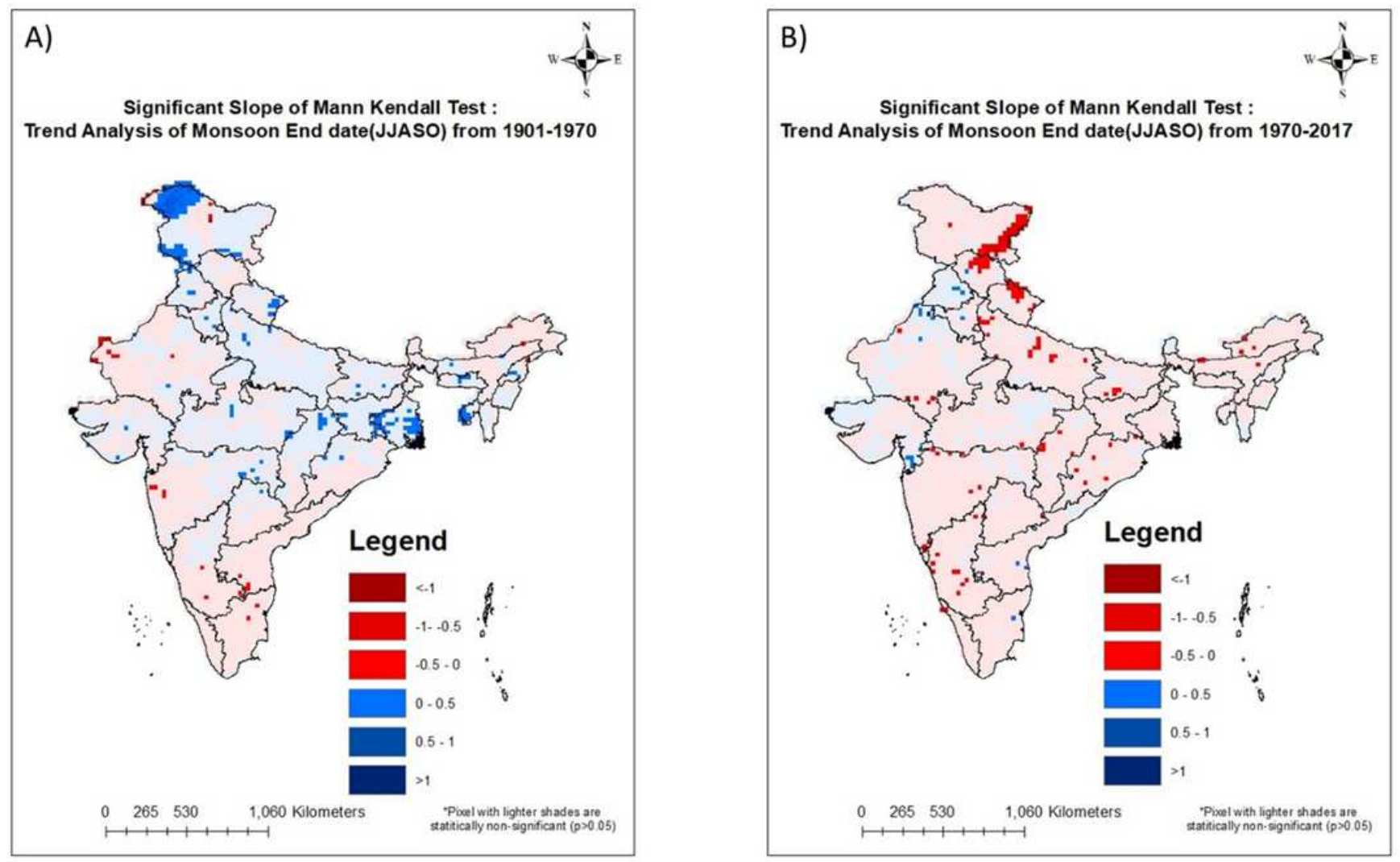

\section{Figure 8}

Withdrawal of Monsoon significant trend and Sen's Slope Estimates. A) 1901-1970 \& B)1971-2017

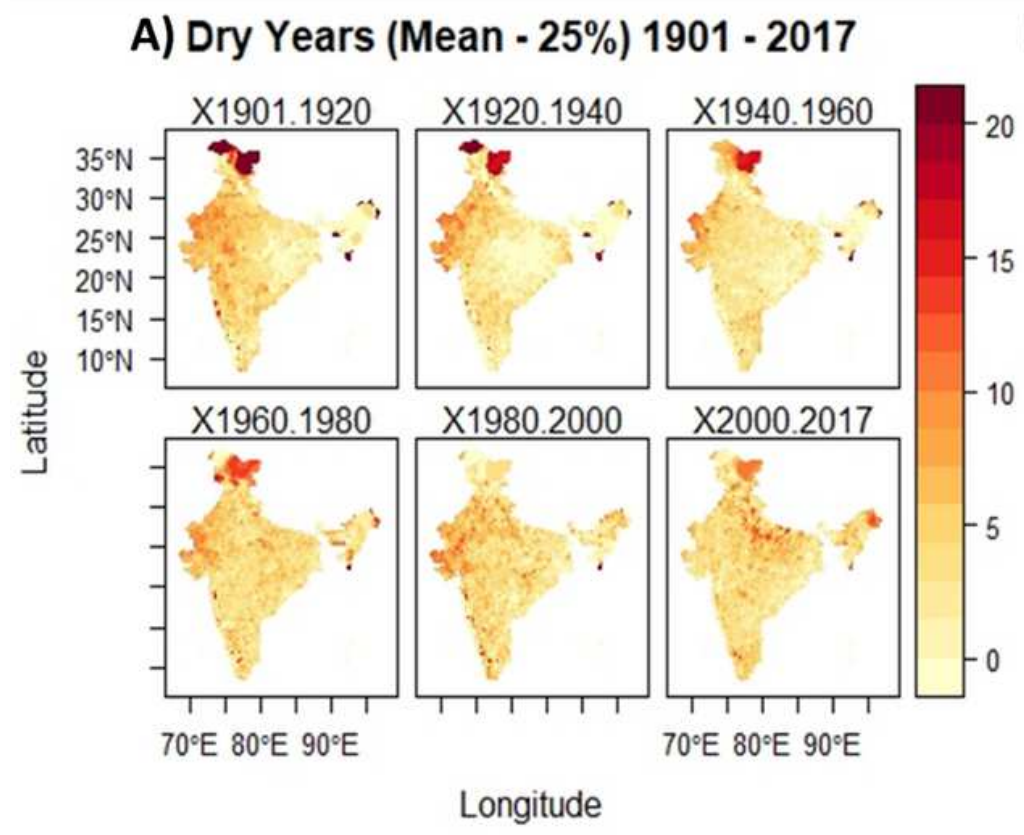

B) Wet Years (Mean + 25\%) 1901 - 2017

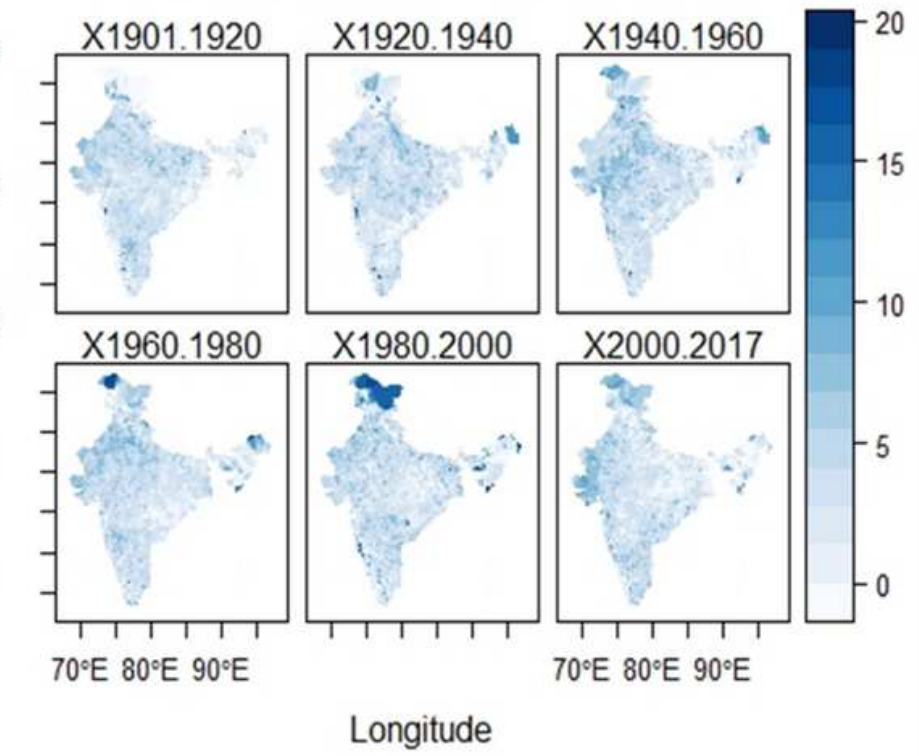

Figure 9 
Vicennial Extreme Years Frequency Mapping. A) Dry years (<Mean- $25 \%$ ) \& B) Wet years (< Mean $+25 \%)$

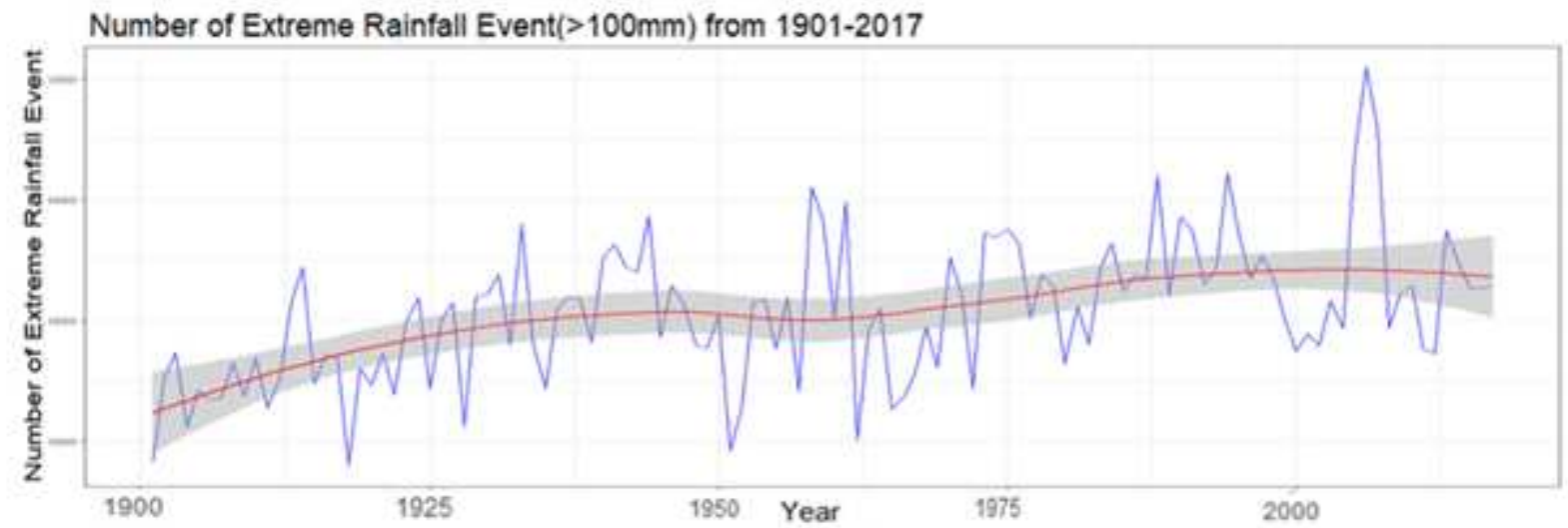

Number of High Rainfall Event $(>65 \mathrm{~mm})$ from $1901-2017$

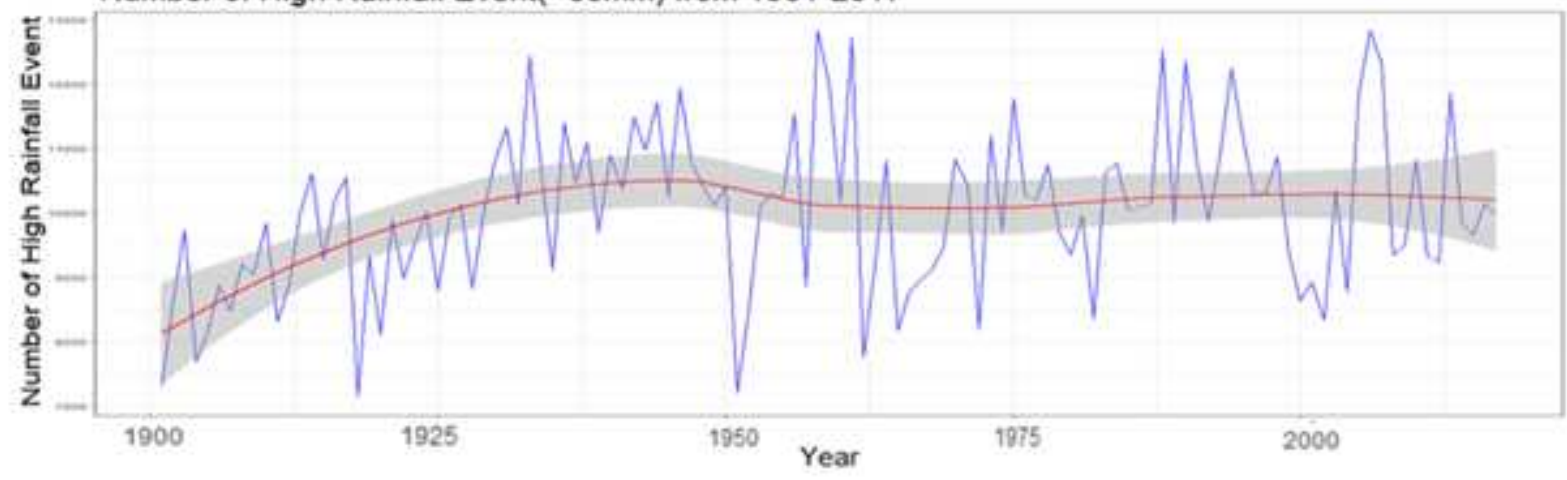

\section{Figure 10}

Number of Incidences with very high rainfall events. A) more than $65 \mathrm{~mm}$ Rainfall in 24 hours, B) more than 100 mm Rainfall in 24 hours. Red Line is the LOESS Regression Line (the smoothed trend line, Appendix 1). 

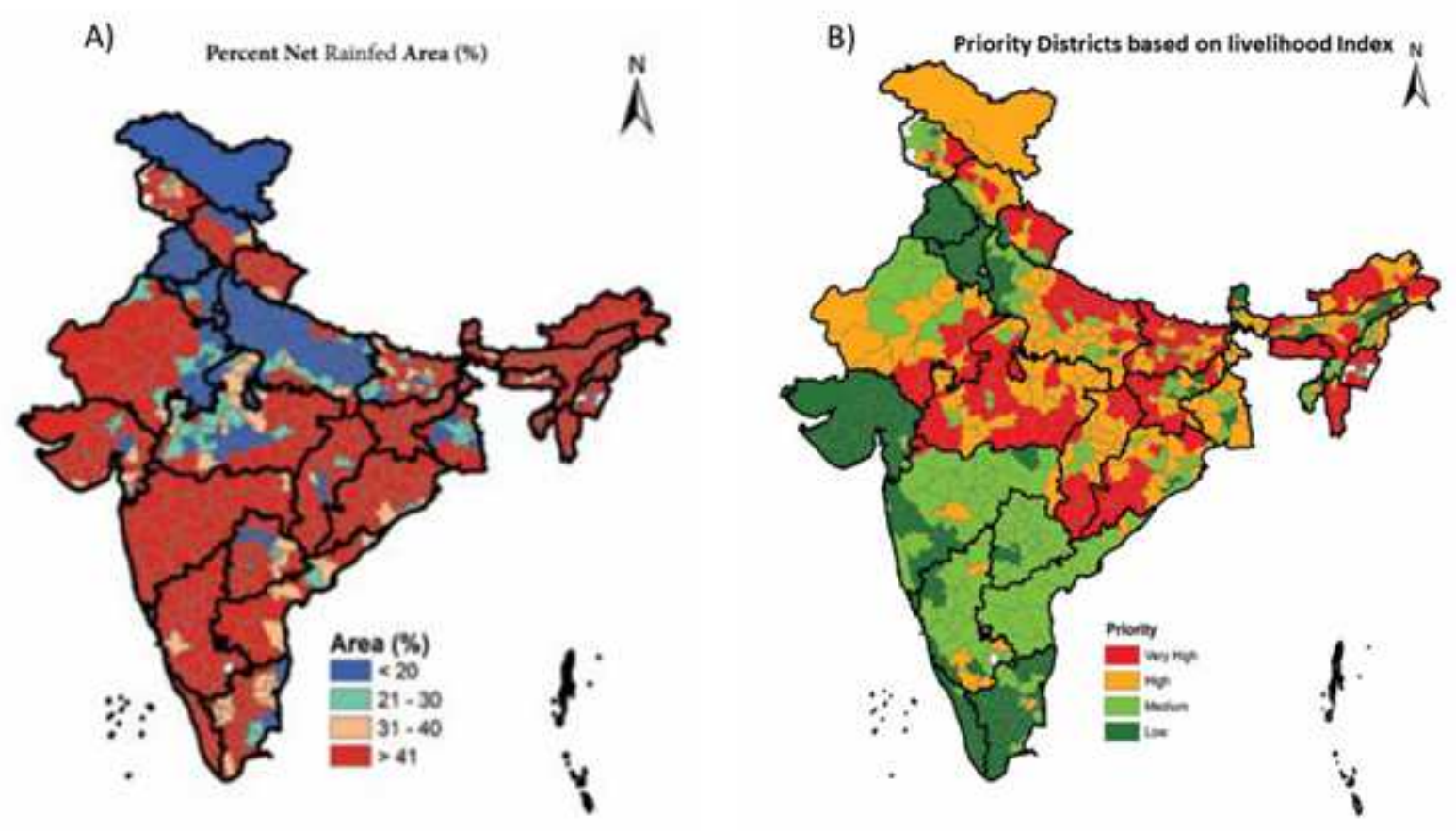

Figure 11

Percentage Irrigated Area out of Net Rainfed-Area (District-wise) (NRAA, 2020)
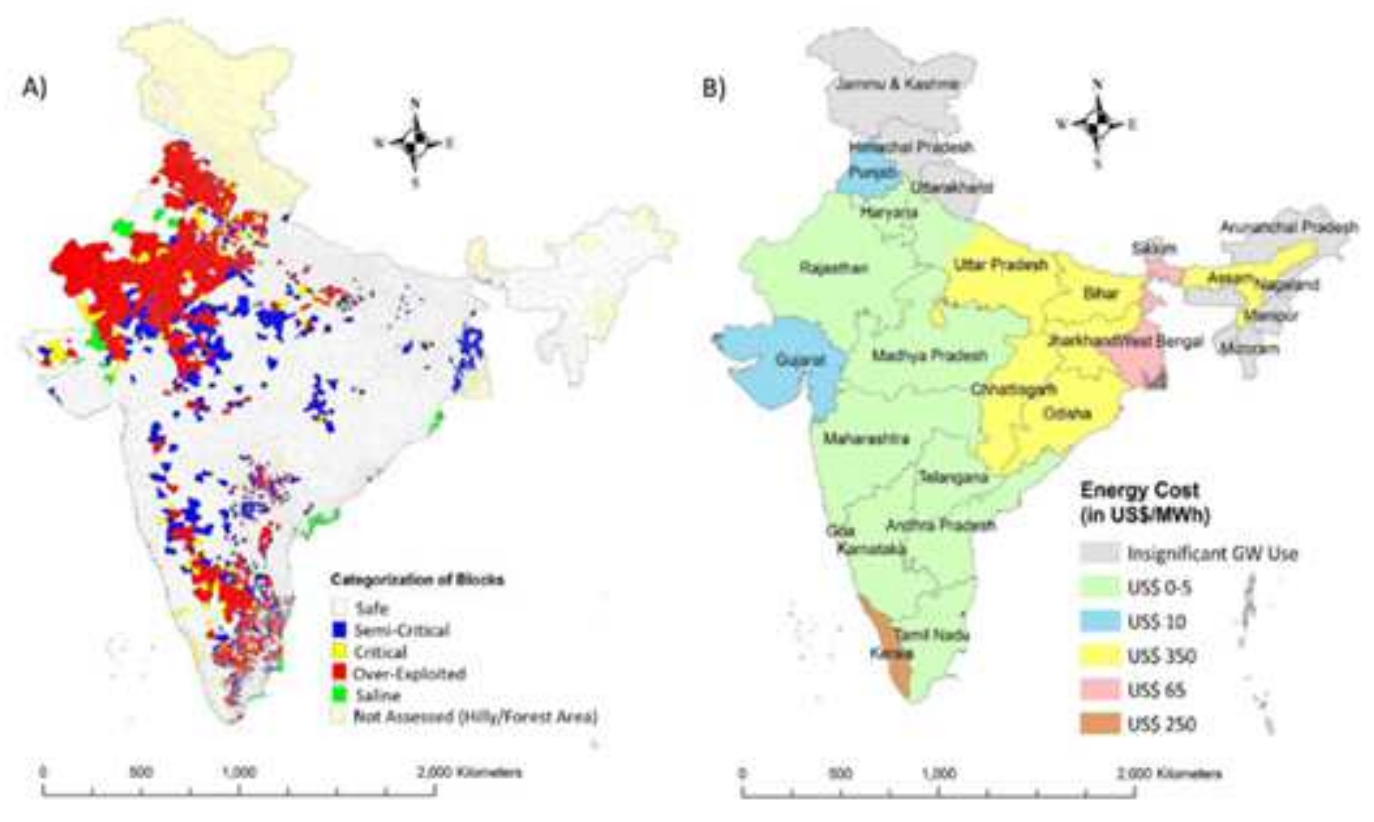

Figure 12

(A) Stage of Groundwater Development in India (B) Energy Cost of Irrigation (Rajan, Ghosh and Shah, 2020) 